ESTUdios INTERNACIONALES I 58 (2007) - ISSN 07I6-0240 • 59-99

Instituto de Estudios Internacionales - Universidad de Chile

\title{
Las empresas multinacionales en la globalización. Relaciones con los Estados
}

\section{Multinationals and globalization: relationships with States}

\author{
Raul Allard Neumann*
}

\section{Resumen}

El artículo aborda las empresas multinacionales (EMN) como actores del sistema internacional actual, que se caracteriza por la globalización de los intercambios comerciales y sus repercusiones en otros campos. Aunque representan solo una fracción del empleo, al organizarse a escala internacional las EMN se adaptan a la globalización como elemento dinámico de la economía mundial y vehículo para la inversión extranjera directa (IED) perseguida tanto por los países desarrollados como por los países en desarrollo. Al mismo tiempo, son objeto de discusión respecto de distintos puntos: efectos en los mercados locales y en la competencia, relaciones con los Estados de la casa matriz y los Estados anfitriones, y nuevos desarrollos y efectos en el medio ambiente y en las condiciones laborales. También existe una creciente -aunque minoritaria-corriente de transnacionalización e inversiones de las EMN desde los países en desarrollo. Se centra la atención en América Latina -y las empresas «translatinas»- y Chile, con su economía abierta y sus acuerdos comerciales, y se formulan algunas observaciones para aprovechar la actividad multinacional y la globalización en beneficio de estos países y sus pueblos.

PAlabras Clave: empresas multinacionales, globalización, inversión extranjera directa, América Latina, Chile.

Profesor de Política Internacional, Pontificia Universidad Católica de Valparaíso (rallardn@ yahoo.es). Recibido el 14 de septiembre de 2007, aceptado el 25 de octubre de 2007. 


\section{Abstract}

This article deals with multinational corporations (MNC) as actors within the international system, in the era of globalization, free trade and worldwide commercial markets. Even though MNCs represent only a fraction of total employment, they are important because of their adaptability to globalization and as a channel for direct foreign investment (DFI) pursued both by developed and developing countries. At the same time, MNCs are subject of discussion in issues such as: effects on competition and local markets, relationships with Governments both of headquarters and of host countries, and recent developments in labor and environmental issues. There is also a growing but minority trend of transnationalization and DFI by corporations of developing countries. The analysis focuses on Latin America - and «translatin» corporationsand Chile, with its open economy and trade agreements, and some suggestions are offered so that these countries and their peoples can take advantage of globalization and multinational activity.

KEYWORDS: multinational corporations, globalization, direct foreign investments, Latin America, Chile. 


\section{Propósito y contexto GLOBAL}

Si bien desde los tiempos de los grandes descubrimientos geográficos las potencias marítimas europeas organizaron o autorizaron grandes empresas que operaban y comerciaban con las colonias de ultramar, la consideración de las empresas multinacionales (EMN) como actores en el sistema internacional solo se generalizó hace tres o cuatro décadas y en ese carácter son mencionadas en distintos textos de política internacional, particularmente de Estados Unidos y Europa. Sin embargo, en nuestro país y región se ha prestado escasa atención as esta disciplina.

En este artículo se entregan algunos elementos que permiten apreciar la naturaleza, importancia y problemática de las EMN como actores en el plano de la política internacional, -más allá de su rol específico económico y empresarial-, en interacción con otros actores y particularmente con los Estados, y en un contexto determinado, que es el del proceso de globalización de las últimas décadas del siglo XX e inicios del actual. Se trata de identificar algunas constantes de esas interacciones. La perspectiva de análisis corresponde a la política internacional, y por la naturaleza del tema se tocan aspectos de política económica y normativa jurídica.

Por su propia naturaleza, estas empresas fueron objeto de intensas discusiones de tipo ideológico hace 30 o 40 años, en el marco de la ampliación de los merca- dos y de una creciente interdependencia, aún en un contexto de Guerra Fría.

Actualmente se considera que las EMN son parte de los actores emergentes, como lo son también diversos movimientos transnacionales, se reconoce su adaptación a la globalización y constituyen en sí mismas una característica de ese proceso. A la vez, son objeto de debate y son variadas las visiones que se tienen sobre el rol de las EMN, según sea la posición de los comentaristas sobre dicho proceso -más globalistas o más escépticos o críticos- y según sea también el enfoque teórico que se utilice para el análisis, desde las perspectivas realista, transnacional, institucionalista liberal, radical u otra.

Las EMN no actúan en el vacío ni son reguladas por una sola normativa nacional y por eso el ámbito del análisis es tanto la globalización y los intentos de reglamentación a nivel internacional, como las políticas y regulaciones de los países en que operan, referidas a la inversión extranjera directa y a otras materias conexas, como la libre competencia y los acuerdos de libre comercio.

Estas empresas han sido un elemento principal en la expansión del comercio internacional, en el contexto de la globalización. Un académico italiano, Fulvio Attiná, sostiene que el mercado mundial, «más que un mercado de intercambio de productos fruto de estrategias de producción y reproducción del capital interno de la economía nacional, es actualmente un mercado de transferencia de trabajo, 
productos y créditos de un país a otro en el marco de estrategias de empresas que, mediante esa transferencia, minimizan los costes de producción y maximizan la capacidad productiva». La acumulación de capital está vinculada con el rendimiento de la economía nacional, pero también depende de las estrategias y «de los comportamientos de las empresas multinacionales y de las empresas cuyas estrategias de producción están en función del marcado mundial» (Attiná, 2001: 66).

Estas interacciones se dan en el contexto de la globalización, concebida como el hecho de los intercambios a nivel mundial que conforman un gran mercado global, proceso que tiene variadas ramificaciones más allá de lo económico y que involucra fuertes cambios -y es afectado- por cambios acelerados en materia de transportes y medios de comunicación, ciencia y tecnología, en particular en tecnologías de la información, y en las interacciones culturales y la propia reafirmación de las identidades culturales.

Coincidimos también con Castells, quien sostiene que la globalización «es el proceso resultante de la capacidad de ciertas actividades de funcionar como unidad en tiempo real a escala planetaria» (Castells, 2006:15). Se habla de la «desterritorialización» como una de las características del proceso, en particular por la utilización de nuevas tecnologías de la información, en tanto otros contraargumentan que «el territorio como espacio sustancial -no ya solo virtual- no ha desaparecido ni desaparecerá» (Randle,1999: 13). A mi juicio, no estamos aún en una sociedad global -como lo sostienen algunos autores como Octavio Ianni- (Ianni, 2004), pero sí estimo que la globalización es la característica definitoria de la economía internacional actual y afecta directamente el sistema político internacional. Reconociendo que es un proceso que encierra peligros y amenazas estimamos que para América Latina y Chile la inserción plena en la globalización es un desafío positivo.

Cabe clarificar de partida, como lo hace Castells (Castells, 2006: 16), que «la economía global no es, en términos de empleo, sino una pequeña parte de la economía mundial. Pero es la parte decisiva. La economía global incluye, en su núcleo fundamental, la globalización de los mercados financieros cuyo comportamiento determina los movimientos de capital, el crédito, las monedas y, por tanto, las economías en todos los países». El mismo autor menciona como elementos de la globalización de la economía, el creciente comercio internacional, el aumento de la inversión extranjera directa (IED), la globalización de una parte esencial de la producción de bienes y servicios por medio de las EMN, la interpenetración de mercados de bienes y servicios, la formación de un mercado global de trabajadores cualificados y las migraciones de mano de obra desplazada por las crisis económicas.

Una investigación centrada en América Latina y su matriz sociopolítica identifica seis características de la economía 
global, incluyendo la intensificación de la competencia global y el surgimiento de nuevos centros de producción; la proliferación, expansión y reestructuración de empresas transnacionales; el entorno tecnológico( con rápidos avances en transportes y comunicaciones) y de política internacional (hegemonía de Estados Unidos, políticas económicas de los Estado-naciones, formas de integración regional económica como la Unión Europea, NAFTA y el Mercosur); un sistema financiero global y desigualdades globales crecientes tanto entre regiones mundiales como al interior de los países (Garretón y otros, 2004: 41).

En este marco global, mencionaremos los tipos de interrelaciones de estas empresas con los Estados, tanto de origen como anfitriones y también, aunque sea tangencialmente, las reacciones y posiciones que adoptan frente a las EMN otros actores transnacionales emergentes de la sociedad civil internacional, como también las propias organizaciones no gubernamentales que agrupan a las corporaciones multinacionales a nivel mundial.

Sin duda, esta temática incide en un área dinámica, como lo muestra el debate en torno a la globalización y los comentarios críticos «desde dentro « del sistema, como el caso de Joseph Stiglitz quien, junto con formular críticas a los organismos internacionales de fomento y regulación de la economía mundial (FMI , Banco Mundial) en sus «recetas» poco matizadas de políticas hacia los países en desarrollo, lo hace con la perspectiva de que la globalización funcione ${ }^{1}$.

En la actualidad, las EMN tienen creciente presencia en América Latina, facilitada por las políticas de apertura económica y regionalismo abierto preconizada en los años noventa por la CEPAL (CEPAL, 1994). Además, aunque son abrumadoramente un fenómeno originado en las grandes potencias industriales, también operan en el mercado internacional EMN de países en desarrollo y, concretamente, de América Latina y Chile, lo que ofrece una nueva arista al análisis.

\section{TRAyectoria DE LAS EMN}

Algunos autores se remontan a comerciantes griegos y fenicios como los precursores y a compañías de comercio con colonias en los siglos XVII y XVIII: la compañía española de las Indias Occidentales, la British East India Company, la Hudson Bay Company, la Levant Company, y la compañía holandesa de las Indias Orientales.

El proceso a partir de la post Segunda Guerra Mundial

No hay dudas de que a partir de la post Segunda Guerra Mundial se aceleró la tendencia a instalar opera-

1 Joseph Stiglitz ha desarrollado su pensamiento en obras tales como El malestar de la globalización (2003) y Cómo hacer que funcione la globalización (2005). 
ciones de empresas en distintos países y continentes, proceso que fue liderado por empresas cuya sede central se encontraba en los Estados Unidos.

Se atribuye a David Lilienthal haber acuñado el término de «empresa multinacional» en 1960 para referirse en general a las que tienen sede en un país y operan y se organizan también bajo las leyes de otros países.

En 1971, Raymond Vernon publicó su estudio Soberanía en peligro (Sovereignty at Bay), posteriormente traducido al castellano (Vernon, 1983) en el cual abordó con visión positiva el tema de las multinacionales, su naturaleza y las relaciones con el Estado-nación, que tuvo repercusión en los medios académicos norteamericanos. Según él, un punto fundamental era el conflicto entre las fuerzas del nacionalismo en lo económico y las fuerzas económicas que presionaban por una integración mundial. En su opinión, la creciente interdependencia económica y los avances tecnológicos en las comunicaciones y los transportes estaban convirtiendo al Estado-nación en un anacronismo.

Conforme a esta visión, las empresas multinacionales personificaban la idea liberal de una economía mundial interdependiente y parecían suficientemente fuertes como para sobrevivir por sí solas. Habían logrado que la producción, el marketing y la inversión se organizaran más a escala global que en términos de las economías nacionales. En este sentido, las EMN apuntarían a una transformación mayor de las relaciones entre países desarrollados y en desarrollo, pues las corporaciones matrices originadas en países desarrollados no solo producían en sus propios territorios sino que la localización de las industrias manufactureras se trasladaría crecientemente a países en desarrollo.

Vernon explicaba a comienzos de los años setenta la salida al extranjero de las EMN mediante la teoría de los «ciclos productivos»: las multinacionales norteamericanas tenían ventajas comparativas en la innovación de productos debido al tamaño de su mercado y a su capacidad de invertir en I+D. En una primera fase o ciclo, el producto se exporta desde el país base pero luego la tecnología se difunde, aumenta la demanda y aparecen imitadores. Para prevenir el ingreso de otras firmas al mercado, la EMN del producto original instalaba plantas en otras economías.

Robert Gilpin, comentando esta tesis, en 1975, abordaba el tema preguntándose quién tenía poder suficiente para que la economía mundial sirviera a sus intereses. En las relaciones entre Estados y empresas multinacionales "cada uno tiene algo que el otro quiere» (Gilpin, 1975). Los Estados controlan el acceso a su territorio, esto es, a su mercado interno, oportunidades de inversión y fuentes de materias primas. Por su parte, las corporaciones cuentan con capital, tecnología y acceso a mercados mundiales.

Según Gilpin, de acuerdo con la tesis de la «soberanía en peligro,» las ventajas estaban siempre de parte de las empresas. Sin embargo, señala que 
el éxito de las EMN depende de un ordenamiento político favorable. «Si ese orden cambia, también lo hace la fortuna de las multinacionales».

\section{El debate en los años sesenta y setenta}

En esos años el tema también se discutía en sus aspectos ideológicos (imperialismo económico) y sus efectos en el desplazamiento del mercado de empresas de los países en desarrollo donde se instalaban, competencia desleal a empresas locales o creación de demanda artificial (Atkins, 1977: 133), o porque las subsidiarias en países en desarrollo quedaban obligadas a adoptar procesos y, por ende, tecnologías y bienes de capital de la empresa matriz (Russett y Starr, 1985: 456).

Al término de su estudio de 1971, Vernon señala que «la empresa multinacional parece capaz, como institución económica, de aumentar la productividad y el crecimiento económico totales del mundo en mayor medida que las alternativas concebibles. En algunos tipos de industrias su contribución a la productividad y el crecimiento parece menor que en otros. Aun puede haber industrias donde la existencia de empresas multinacionales perjudique al crecimiento, aunque estas situaciones son probablemente excepcionales» (Vernon, 1983: 255). Agrega que las conclusiones relativas a distribución de beneficios entre países y al interior de ellos era más incierta, que se produ- cían problemas de carácter tributario por la libertad de las empresas "para asignar sus beneficios entre diferentes jurisdicciones» (Vernon 1983: 279) y advertía un nivel de tensiones en el país extranjero asociado con su presencia.

Más que el tema de la "soberanía", preocupaba la sobreposición de jurisdicciones en lo relativo a regulación. El propio Vernon, que en 1971 había expresado que «conceptos tales como la soberanía nacional y el poderío de la economía nacional aparecen curiosamente privados de significado» (Vernon, 1983: 9), atemperó su posición en trabajos posteriores. Al parecer, a Vernon verdaderamente le preocupaban temas como los relativos a "autonomía» $\mathrm{y}$ «control» en las relaciones entre Estados y multinacionales, más que el concepto jurídico de «soberanía», que naturalmente seguía vigente.

Así, había un debate entre los optimistas y los pesimistas respecto del rol y la proyección de las EMN como actores internacionales.

\section{CONCEPTO Y TEORÍAS SOBRE LAS EMPRESAS MULTINACIONALES}

En la actualidad, las empresas multinacionales operan a escala mundial, facilitadas por el proceso de globalización y formando parte de este. Su acción se ha visto favorecida por los cambios políticos ocurridos a fines del siglo pasado, con el término de la Guerra Fría y, de hecho, su carácter de actores internacionales ya no se discute. 
Hay quienes sostienen que constituyen una amenaza para la sociedad, ante la cual los gobiernos son impotentes, y que tienen efectos negativos tanto para el país anfitrión como para el de la casa matriz. En tanto otros -los más-, afirman que no afectan demasiado al país de origen y que normalmente llegan a acuerdos con el país anfitrión para maximizar las ganancias de ambos en términos de beneficios para las empresas e impuestos, empleos y capacidad exportadora para los Estados.

\section{Nomenclatura}

Utilizaremos indistintamente como sinónimos los términos «empresas multinacionales» $\mathrm{y}$ «empresas trasnacionales», que son los más en boga. El primero es más utilizado en el mundo académico y económico. La UNCTAD y la CEPAL, en sus programas e informes, las denominan «empresas transnacionales». Aunque con menor frecuencia, también se las menciona como empresas internacionales o globales.

Forman parte del género más amplio de actores transnacionales que implica esencialmente un tipo de acción no estatal que desde un país se proyecta más allá de sus fronteras, lo que incluye variadas organizaciones no gubernamentales con distintas preocupaciones e «internacionales» de carácter ideológico y que agrupan a movimientos políticos.

Las EMN se presentan como racimos de empresas que operan a escala internacional, vinculadas entre sí mediante una compleja red de relaciones institucionales, de propiedad, de producción, comerciales, administrativofinancieras y tecnológicas, con una sede matriz y una "gran estrategia» comunes (Allard, 2004).

En 1977, el Informe Goldman del Instituto de Derecho Internacional propuso que «las empresas constituidas por un centro de decisión localizado en un país y por centros de actividad, dotados de nombre y personalidad jurídica propias, situados en varios otros países, deben ser consideradas como constituyendo en derecho empresas multinacionales» (Zerka, 1995).

Como hemos visto, estas empresas no representan un nuevo tipo de organización, pero sí una categoría notablemente renovada en su complejidad, volumen, número y capacidad de adaptación a un mundo globalizado.

Robert Gilpin ofrece un concepto instrumental y concreto de EMN: «Simplemente, una firma de una nacionalidad determinada que tiene subsidiarias total o parcialmente propias, al menos en otra economía nacional» (Gilpin, 2000).

De acuerdo con una conceptualización de la UNCTAD, las EMN son originarias de un país -empresa matrizcon actividades estables y control sobre filiales en al menos dos países extranjeros donde se realiza más del 10\% de sus ventas (Guardia, 2001).

El objetivo final es establecer una posición en otra economía. 
Teorías explicativas

Gilpin (Gilpin, 2001: 282 y siguientes) analiza las teorías que explican la expansión de las EMN señalando que la teoría de los ciclos productivos de Vernon, antes mencionada, se desacreditó cuando empezó a cerrarse la brecha tecnológica entre Estados Unidos y otros países. La tesis ecléctica de Dunning enfatiza el factor tecnológico; la teoría estratégica de Porter prioriza la capacidad de las EMN para localizar actividades dentro de la «cadena del valor» de un producto; la posición radical de Hymer, según la cual las EMN invierten en el exterior en búsqueda de algún tipo de ventaja específica o monopólica. La interpretación Estado-céntrica supone que las EMN son fundamentalmente empresas nacionales que compiten entre ellas alrededor del mundo. Según esta tesis, estas firmas estarían estrechamente ligadas y, en último término, dependerían del país o economía de la casa matriz, serían empresas nacionales que conducen negocios internacionales.

Dunning (Dunning, 1985) acentúa algunas características de las EMN que les darían ventajas sobre las empresas nacionales en aspectos tales como su ubicación, el hecho de tener una marca comercial o de poseer una tecnología particular, y al salir al exterior explotan esas ventajas por sí mismas.

Sin duda, es muy amplia la gama de objetivos que impulsan a las EMN a operar en otros países, incluyendo otras mas «tradicionales», como la de evitar aranceles aduaneros, particular- mente hace 30 o 40 años cuando estos eran relativamente más altos, evitar regulaciones muy complejas o exigentes en el país de origen, reducir costos de transporte o aprovechar los incentivos tributarios o de otro orden que ofrezca el países en que se instalan.

Por lo que respecta a América Latina y a la internacionalización de sus propias empresas, existen diversas tesis. Unas, más vinculadas a las estrategias de interacción del Estado y las empresas: la internacionalización obedecería al esfuerzo de las empresas que, de manera singular, con la asistencia del gobierno, actúan de manera sostenida en los mercados externos como parte de una estrategia en que actúan de manera coincidente el Estado, el aparato productivo y el sector académico y tecnológico (Sierralta, 2002: 61).

Para otros, la internacionalización de las empresas de América Latina se enmarca en los procesos de apertura y reestructuración de dichas economías, por lo que no es extraño que en Chile y México, seguidos luego por Argentina, se hayan manifestado tempranamente las tendencias a la internacionalización de empresas locales (Chudnovsky y López,1999: 64).

\section{TIPOS DE EMPRESAS MULTINACIONALES Y PROCESOS DE INSTALACIÓN}

Las empresas multinacionales adquieren diversas formas desde las que intervienen principalmente en activida- 
des de importación y exportación hasta las que hacen inversiones significativas en un país extranjero, las que compran y venden licencias en terceros países y las que permiten a industriales de un país extranjero fabricar sus productos. También, las empresas que abren plantas de manufacturas u operaciones de ensamblaje en otras naciones (Mingst, 2001: 209).

\section{Integración vertical $u$ horizontal}

Algunos estudios recientes distinguen dos tipos de EMN, las verticales y las horizontales.

Las verticales, según el autor español Guillermo De la Dehesa (De la Dehesa 2002: 98), fragmentan su producción geográficamente en etapas del proceso productivo, de acuerdo con la intensidad de los factores de producción. Así, las actividades que requieren de personal más especializado se localizarían en países más desarrollados donde ese personal existe y con costos razonables, en tanto que las actividades intensivas en mano de obra no calificada se ubicarían en los lugares en que esta es más abundante y de menor costo. Algo análogo sucedería con los recursos naturales.

Las multinacionales horizontales serían empresas con multiplicidad de plantas, que replican fundamentalmente la misma actividad productiva en muchas localizaciones, basándose en economías de escala y menores costos del transporte.
Últimamente se ha intentado combinar ambos modelos en uno llamado de "conocimiento-capital», en que se parte de la base de que el conocimiento es geográficamente móvil y constituye un insumo (input) para todas las plantas que fabrican productos múltiples.

Según De la Dehesa, las empresas de tipo vertical operan en mayor medida en países de muy distinto nivel de desarrollo, mientras que las horizontales se dan mayoritariamente en países similares y sitúan el centro de operaciones en el país con mayor mercado nacional. El modelo de "conocimientocapital» se puede dar en ambos tipos de situaciones, localizan su centro de operaciones en el país en que abunda el factor conocimientos especializados y las plantas más grandes en países con mayor mercado o abundancia de mano de obra menos calificada.

\section{Jurisdicción, instalación y funcionamiento}

En términos jurisdiccionales, las EMN son conjuntos de empresas que, normalmente, se instalan como empresas nacionales del país de la filial y cada cual responde al país en que opera. Sin embargo, en la práctica ningún Estado tiene un control completo sobre ellas debido a las dificultades para obtener la información necesaria acerca de las operaciones en su conjunto.

En cuanto a su funcionamiento, pueden distinguirse dos elementos de diversificación, el geográfico y el sectorial. 
Para el primero, la presencia de estas empresas en casi todo el mundo por medio de sucursales habría creado un sistema económico transnacional que trasciende las naciones y las convierte en partes de ese sistema. La diversificación sectorial significaría que, debido precisamente al carácter tecnológico de la empresa transnacional, está capacitada para dirigirse y actuar en muchos sectores de la economía. Naudon y Sepúlveda opinan que esto «supera así la naturaleza monopólica de los antiguos trusts, dedicados a actuar en un solo sector» (Naudon y Sepúlveda 1998: 97).

En cuanto al modo de instalación, más allá del tipo de sociedad legal, predomina la compra de activos y empresas ya existentes, en muchos casos de carácter público, con base en procesos de privatización y en fusiones, adquisiciones y variedad de arreglos interempresas, para adquirir diversos grados de participación o control, fenómenos especialmente dinámicos, según muestran los informes de la UNCTAD.

\section{ELEMENTOS DE LA REALIDAD ACTUAL}

\section{La situación a fines del siglo XX}

Como resultado del desarrollo experimentado por las EMN, según datos de la UNCTAD, en 1999 en todo el mundo había 500 mil empresas filiales de multinacionales, que habían sido fundadas por 60 mil empresas matrices no financieras. Según De la Dehesa, algunas de esas empresas son medianas y aun pequeñas y 50 mil de ellas pertenecerían a países desarrollados (De la Dehesa 2002: 91).

Hacia fines del siglo XX, como lo apunta el mismo autor (De la Dehesa 2002: 101) un 60\% de la IED de empresas multinacionales correspondía a países desarrollados, particularmente Estados Unidos y Europa, en tanto que el $40 \%$ restante iba a países en desarrollo, en especial de Asia y América Latina, con China, Brasil y México como mayores receptores.

La mayoría de las EMN tienen su casa matriz en la tríada Estados Unidos (que se adelantó en el proceso de establecer sedes y plantas en el exterior), Unión Europea y Japón. En menor medida, hay también actividad multinacional originada en China, Malasia, Corea Singapur, Australia, Canadá, etc. También existe IED de países en desarrollo y EMN cuya casa matriz se encuentra en ellos, incluyendo por cierto países de América Latina, como veremos más adelante.

En todo caso, el país en que radicaba el control era claro: de las 500 empresas más grandes, 222 eran de Estados Unidos, 130 de la Unión Europea, 71 tenían su sede principal en Japón, en tanto 8 eran de América Latina.

También se da el fenómeno de empresas cuyas actividades están mayormente globalizadas, y en que más del $50 \%$ de sus activos, ventas y trabajadores se encuentran y operan 
en terceros países, como es el caso de la Royal Dutch-Shell, Nestlé, IBM, Nissan, Volkswagen-Audi y otras. En el caso de las empresas automotrices ello se explica porque están sujetas a mayor regulación, cuotas de importación, contingentes y otras barreras, etc., mientras que en las petroleras las plantas de extracción, exploración y refinerías se encuentran en los países productores.

Después de la Segunda Guerra Mundial, las principales multinacionales se centraron en las manufacturas y las industrias extractivas, mientras que actualmente están muy diversificadas, e incluso un número importante se dedica a los servicios. La IED y las EMN de los propios países en desarrollo es un fenómeno creciente aunque de volumen menor.

La IED en países en desarrollo se ha incrementado fuertemente en las últimas décadas, a un ritmo son precedentes si bien con fluctuaciones. Los Estados compiten para atraer inversiones ofreciendo condiciones favorables e incentivos. Por otra parte, un estudio de la CEPAL muestra que la rentabilidad de los negocios de las empresas que invierten en regiones pobres como el África subsahariana es extraordinariamente alto, en circunstancias de que su carga tributaria en esos países tiende a disminuir. ${ }^{2}$. En esta línea, Ulrich Beck

2 Un análisis en esta línea, en Andrew Mold, «Una propuesta de gravar con impuestos unitarios las ganancias de las empresas transnacionales", Revista de la CEPAL $\mathrm{N}^{\circ}$ 82, p. 37. observa que «las empresas pueden producir en un país, pagar impuestos en otros y exigir gastos estatales en forma de creación de infraestructuras en un tercer país» (Beck 1998: 19).

\section{La inversión y las empresas en los} inicios del siglo XXI

El proceso de IED ha sido monitoreado por la UNCTAD, que se ha ocupado tanto de la inversión como de las empresas trasnacionales. La idea de su programa a estos efectos es ayudar a entender la naturaleza de estas empresas y su contribución al desarrollo y crear un clima favorable a la inversión internacional. Con este fin ha emitido el World Investment Report (WIR), como los de 1994, 1999, 2004, 2006 y el recientemente publicado del $2007^{3}$.

\section{El WIR 2004}

Cuantitativamente, el informe de 2004 menciona 31 mil empresas transnacionales con más de 900 mil filiales

3 El proceso de IED, es monitoreado desde 1975 por las Naciones Unidas y desde 1993 por el programa EMT de la UNCTAD. El informe correspondiente a 2004 revela un incremento de la tendencia hacia los servicios, mientras que el de 2006 refuerza la idea de la IED desde las economías en desarrollo y en transición. El informe de 2007, publicado en octubre del presente año, hace hincapié en el tema de las corporaciones transnacionales, la industria extractiva y el desarrollo. 
en el extranjero. Destacaremos algunos puntos del Informe que de alguna manera refleja la información «oficial» de la comunidad internacional de un proceso muy complejo y en que concurren intereses muy diversos:

a) Monto de la IED en 2003. Las entradas mundiales por concepto de IED en ese año alcanzaron a $560 \mathrm{mil}$ millones de dólares, cifra importante pero que significó una disminución por tercer año consecutivo en relación con el año anterior. La caída obedeció fundamentalmente a la baja de $25 \%$ de las inversiones en los países desarrollados, pese a lo cual captaron la mayor parte (367 mil millones de dólares) frente a los 172 mil millones que recibieron los países en desarrollo. La IED aumentó en 111 países y se redujo en 82 . Por regiones del mundo en desarrollo, se elevaron las inversiones en África, Asia y el Pacífico y disminuyeron aquellas en América Latina y el Caribe. Un dato que refleja las disparidades de la globalización es que los 50 países menos adelantados -los más pobres- prácticamente no reciben inversión, 7 mil dólares en total (UNCTAD, 2004:1 Y 2).

b) Fusiones y adquisiciones de empresas y acuerdos bilaterales sobre inversión y tributación. En 2003 las fusiones y adquisiciones transfronterizas, conocidas como FAS, alcanzaron un total de 297 mil en todo el mundo y en el primer semestre de 2004 aumentaron un 3\%. Las ganancias reinvertidas volvieron a crecer, alcanzado según el informe «una cifra sin precedentes». Se señalan tres componentes de las corrientes de IED: ganancias reinvertidas, participaciones accionarias y préstamos interempresas. El informe de la UNCTAD señala que en 2003 en todo el mundo se produjeron 244 cambios de las leyes y reglamentos que regulan las inversiones, 220 de los cuales tuvieron por objeto una mayor liberalización. Asimismo, menciona que ese año se concertaron 86 tratados bilaterales sobre inversiones (TBI) y 60 tratados sobre doble tributación (TDI) con lo cual las cifras totales se elevan a 2.265 y 2.316 , respectivamente (UNCTAD, 2004: 1 y 2). También se celebaron tratados denominados de Promoción y Protección de Inversiones Recíprocas.

c) Las mayores empresas transnacionales. Concentración. El fenómeno de las empresas multinacionales o trasnacionales se da fundamentalmente en países desarrollados, como lo muestra la lista de las 25 mayores según el monto de sus activos en el extranjero, que encabezan General Electric (Estados Unidos), Vodefone Group Plc. (Reino Unido); Ford Motor Co. (Estados Unidos); British Petroleum Co. (Reino Unido) y General Motors (Estados Unidos). La lista incluye 5 empresas de Estados Unidos, 2 del Reino Unido, dos de Japón, 5 de Francia, 5 de Alemania, 2 de Italia, 1 de China/Hong-Kong, 1 de Suiza, 1 de Australia y la Royal Dutch-Shell, que es compartida entre los Países Bajos y el Reino Unido. Los rubros más recurrentes son electricidad, 
exploración, refinación y distribución de petróleo, telecomunicaciones, autos, gas y agua, medios de comunicación, industria farmacéutica, y otras de giro diversificado, etc. Según el informe, el proceso seguía estando bastante concentrado: «...en 2002, las 100 mayores ETN que representaban menos del $2 \%$ del universo mundial de las ETN, sumaban entre todas el $14 \%$ de las ventas de las filiales extranjeras en todo el mundo, el $12 \%$ de los activos y el $13 \%$ de sus plantillas» (UNCTAD, 2004: 6).

d) Creciente participación de las empresas trasnacionales de países en desarrollo e inversión externa. El caso de Chile. El informe de la UNCTAD del 2004 puntualiza que siguiendo la tendencia de años anteriores, los países desarrollados son el motor de la IED. Sin embargo, "las ETN de países en desarrollo también contribuyen cada vez más a estimular el crecimiento de estas inversiones». Porcentualmente subieron del $6 \%$ a mediados de los 80 a $11 \%$ en la década de los 90 para estabilizarse en el 2001-2003 en el 7\%, con un promedio anual de 46 mil millones de dólares, «actualmente, aquellas empresas controlan alrededor de una décima parte del monto acumulado mundial de salidas de IED», con 859 mil millones de dólares en 2003, lo que equivale a un aumento de $8 \%$. Las 50 principales ETN de países en desarrollo se están transnacionalizando a un ritmo más rápido que sus homólogas de países desarrollados. Las 25 ETN de países en desarrollo que tienen mayores activos en el exterior no incluyen empresas chilenas (sí dos de Brasil, una de Argentina y una de México). Chile figura entre los países que más invierten en el extranjero, lo que se mide en proporción de la formación bruta de capital fijo. El país con mayor porcentaje de inversión externa es, con mucho, Singapur, con $36.3 \%$, mientras que Chile se sitúa en cuarto lugar con un $7.4 \%$ (después de Hong-Kong, China y Taiwán y más que Malasia, India, China, Brasil, etc. (UNCTAD, 2004: 6 y 7).

e) Relocalizaciones, deslocalizaciones y servicios. El informe señala la creciente tendencia a la relocalización de un amplio abanico de funciones empresariales, alentada por la fuerte competencia por atraer IED por parte de los organismos encargados de su promoción, como Pro Chile y el Ministerio de Relaciones Exteriores en Chile. Igualmente, menciona la tendencia creciente a la inversión en servicios con una nueva dimensión. Hasta hace pocos años, la característica de los servicios es que debían producirse y consumirse en el mismo lugar en que se consumían. En los últimos 10 años y con base en las TIC, un número creciente de servicios ha podido producirse en un lugar y consumirse en otros. Se hacen comercializables mediante un proceso de deslocalización (offshoring). El informe también señala posibles desventajas que los países deben tener en cuenta y superar en este tipo de inversiones (UNCTAD 2004: 22 a 24). 
Informe de la UNCTAD sobre las inversiones en el mundo en 2006. Inversiones en países desarrollados $y$ en desarrollo

Este informe (UNCTAD, 2006) mostró las tendencias de las corrientes de IED. Las entradas mundiales de este tipo de inversión aumentaron considerablemente en 2005, alcanzando a 916 mil millones de dòlares, $29 \%$ más que en 2004 , con un marcado incremento en países desarrollados.

El informe se centró en el aumento de la IED de las empresas transnacionales de las economías en desarrollo y en transición. Señala que este fenómeno fue especialmente notable en los diez años anteriores y que las nuevas relaciones que esas empresas transnacionales están estableciendo con el resto del mundo repercutirán en la configuración del paisaje económico mundial de los próximos decenios. En el caso de las empresas latinoamericanas, el informe destaca una estrategia agresiva de expansión en áreas en que las EMN de países desarrollados estaban disminuyendo sus operaciones ${ }^{4}$.

Esta tendencia también fue destacada por la OCDE que precisó que las EMN basadas en países en desarrollo y emergentes estuvieron más activas en la adquisición de empresas en el área de sus miembros (OCDE, 2006).

4 El informe (UNCTAD, 2006: 73) menciona a la firma mexicana Telmex en telecomunicaciones y a las firmas chilenas de retail Falabella y Farmacias Ahumada.
En 2005, los flujos de IED a América Latina y el Caribe aumentaron levemente, en un 3\%. Por su parte, en América del Sur las entradas de capital incrementaron un $20 \%$ para alcanzar a 45 mil millones de dólares, registrándose los mayores incrementos en los países andinos. La IED en Argentina creció en 9\% y la dirigida a Brasil y Chile se redujo en un $16 \%$ y un $7 \%$ respectivamente, aunque siguió siendo significativa.

Las salidas de IED a la región subieron un $19 \%$, a 33 mil millones de dólares, de los cuales 14 mil millones se originaron en centros financieros supranacionales. Con exclusión de estos últimos, México, Colombia, Brasil y Chile (2.100 millones de dólares) fueron los principales inversores extranjeros (UNCTAD, 2006).

En 2005 algunos países, como Bolivia y Venezuela, evolucionaron hacia una mayor intervención del Estado en la economía, y hacia cambios en las políticas que afectan a los inversionistas extranjeros o a industrias en que estos predominan.

\section{El Informe de la UNCTAD sobre} las inversiones mundiales en 2007

Este informe analiza la IED del 2006 y pone especial atención en el papel de las EMN en la extracción de petróleo, gas, metales y minerales (UNCTAD, 2007).

En 2006 las corrientes mundiales de IED aumentaron por tercer año 
consecutivo, crecimiento compartido tanto por países desarrollados como en desarrollo. Los flujos globales crecieron un $38 \%$, situándose en 1.3 mil millones de dólares, lo que marca el tercer año consecutivo de expansión.

Según los datos más recientes de la UNCTAD, las inversiones corresponden a unas 78 mil empresas transnacionales, que operarían mediante alrededor de 780 mil filiales extranjeras. Se calcula que las ventas de dichas empresas subieron un $18 \%$.

Las entradas de IED de países desarrollados aumentaron un $45 \%$ (hasta 857 mil millones de dólares, y los flujos a países en desarrollo y economías en transición alcanzaron a $379 \mathrm{mil}$ millones y 69 mil millones de dólares, respectivamente (UNCTAD, 2007).

Estados Unidos recuperó su posición como principal país receptor.

A nivel regional, la IED en América Latina y el Caribe aumentó en $11 \%$ alcanzando a 34 mil millones de dólares, siendo los principales receptores Brasil (19 mil millones) y México (18 mil millones), en tanto Chile se ubicó en tercer lugar con casi 8 mil millones, un aumento de $14 \%$ en relación con 2005 , lo que representa un $28 \%$ del total de formación bruta de capital en la economía ${ }^{5}$.

Los países latinoamericanos duplicaron con creces su inversión en el exterior, que alcanzó a montos cercanos a los 50 mil millones de dólares, proce-

UNCTAD, 2007 y análisis del Diario Financiero, 17 de octubre de 2007. so liderado por Brasil, México y Chile, este último con salidas de capital por alrededor de 2.900 millones de dólares, con un crecimiento del $30 \%{ }^{6}$.

La inversión "sur-sur» y las «translatinas». Inversiones en la región según la CEPAL $e$ inversiones y ventas de empresas latinoamericanas y chilenas

Como ya mencionamos, aunque en un volumen menor en términos relativos, se registra una creciente inversión «sur-sur» de países en desarrollo. Según datos de 2005, la cuarta parte de la inversión en países emergentes provino de países de la misma condición ${ }^{7}$.

En América Latina, la CEPAL ha hecho seguimiento a la inversión "sursur» de las propias empresas latinoamericanas, las «translatinas». Como se ha visto, Brasil y México son los países que concentran la mayor parte de los montos que las empresas latinoamericanas invierten en el exterior. Entre las empresas mayores se mencionan la telefónica mexicana América Móvil, la estatal brasileña Petrobrás - «que pretende invertir 7 mil millones de dólares en América Latina en los próximos 10 años, ubicándose entre las cinco compañías con más inversiones en la región»-, Cemex, Telmex, y Techint

6 UNCTAD 2007 y análisis del Diario Financiero, 17 de octubre de 2007.

El Mercurio, Santiago, Nicolás Seller Flater, «América Latina Inversión: Gigantes regionales», 31 de mayo de 2006. 
(de Argentina, en el rubro tecnológico), en tanto que las de empresas chilenas son significativas -además de minería y energía- en el rubro del retail (Cencosud, Falabella y Ripley) con inversiones particularmente en Perú, Colombia, Argentina y otros países ${ }^{8}$, señalándose que «el retail protagoniza la apuesta local por el mercado latinoamericano con 3 mil millones de dólares hacia el año 2010.

Chile fue el tercer país de la región que recibió más capitales internacionales, después de Brasil y México, desplazando a Colombia. En lo relativo a inversión directa en el exterior, el mismo informe de la CEPAL menciona que en 2006 las cifras demostrarían que las empresas de América Latina se están internacionalizando a un ritmo más rápido?

Según un ranking de julio de 2007, de las 500 empresas que en 2006 se contaban entre las más grandes de América Latina, dominaban Brasil y México con 207 y 111 empresas respectivamente, seguidos de Chile con 63, Argentina con 41 y Colombia con 35. La mayor empresa es PDVSA de Venezuela en el sector petróleo y gas. Entre las diez primeras hay 7 de México, 2 de Brasil y 1 de Venezuela.

En el caso de Chile, dentro de las

El Mercurio, Santiago, art. citado.

9 El Mercurio, Santiago. En América Latina: Chile salta al tercer lugar como receptor de inversión extranjera, 4 de mayo de 2007, p. B5. El artículo contiene declaraciones de José Luis Machinea, Secretario Ejecutivo de la CEPAL.
170 empresas de mayores ventas se sitúan, con su respectivo lugar: Codelco (12), Escondida (28), empresas Copec (30), ENAP (37), Enersis (39), Cencosud (52), Falabella (78), Antofagasta PLC (87), Sudamericana de Vapores (89), Collahuasi (109), D\&S (110), Lan (115), Celco (126), Los Pelambres (133), Endesa (144), Compañía Manufacturera de Papeles y Cartones (157), Telefónica (158), Minera Sur Andes (161) y Molinet $(170)^{10}$. Un estudio reciente de la Direcon, en Chile, señala que la inversión externa en el período 1990-2004 ascendió a 34 mil millones de dólares, con 1.600 proyectos en 63 países, en los rubros de energía, electricidad y gas, industria manufacturera y comercio (retail), con $75 \%$ de la inversión concentrada en Argentina, Brasil y Perú ${ }^{11}$.

En lo que respecta a la fusión de Falabella y D\&S, se ha señalado que la empresa fusionada sería la segunda en el sector del retail en América Latina, detrás de Wal Mart de México y superando a Pao de Açucar (Brasil), Cencosud (Chile) y Soriana Organización y Comercial Mexicana (México) ${ }^{12}$.

10 El Mercurio, Santiago, 21 de julio 2007, José Troncoso, "63 empresas chilenas venden el equivalente al PIB en 2006", citando datos del ranking publicado en la revista América Economía.

11 La Tercera, 5 de enero de 2007, p. 30, Ximena Bravo, «Argentina, Brasil y Perú concentran $75 \%$ de la inversión chilena en el exterior».

12 Estrategia, 15 de mayo de 2007, p. 17, «Falabella y D\&S liderarán retail en Chile y serán segundos en Latinoamérica». 
En el contexto de la globalización a menudo se publican ránkings de distinto tipo: así, Santiago aparece como la ciudad número 53 en producción económica ${ }^{13} \mathrm{y}$ entre las mejores empresas para trabajar en Chile figuran diversas multinacionales $^{14}$, particularmente extranjeras.

\section{Tendencias}

En la práctica, la condición de las empresas transnacionales como vehículo para la inversión extranjera directa entraña que exista un conjunto de stocks de capital, conocimientos y tecnología, lo que para los países en desarrollo implica disponer de una fuente importante de capital humano y cambio tecnológico que puede incrementar su productividad e influir positivamente en su crecimiento. Esto explica su presencia, prácticamente en todo el mundo y en particular en países como Chile que se han incorporado resueltamente en la globalización, aunque reconociendo sus peligros.

Lo anterior coexiste con relaciones complejas con los gobiernos que ven mermada su capacidad de acción frente a decisiones o exigencias de las empresas multinacionales que los afectan. Esto se advierte, por ejemplo, cuando las empresas extranjeras eluden o reducen la tributación en los países

13 Diario Financiero, 8 de marzo de 2007, «Santiago, la ciudad número 63 en ranking de producción económica».

14 Revista Capital No 212, 7 al 20 de septiembre de 2007, p.67, «GPTW, Campeones 2007». en que tienen filiales, buscando los denominados «paraísos fiscales».

Algo análogo sucede con los trabajadores sin calificación y los sectores productivos de países en desarrollo que quedan desplazados por la irrupción de las transnacionales. Y, en el caso de los países desarrollados, con los sindicatos que combaten «la exportación» de empleos, particularmente industriales, que emigran hacia países en desarrollo.

\section{PRincipales funciones \\ DE LAS EMN COMO ACTORES INTERNACIONALES}

Naturalmente, como toda empresa, las EMN desarrollan un giro determinado -o varios según su grado de diversificación-y buscan maximizar el lucro y las ganancias. Lo que nos interesa aquí es identificar algunas tareas o funciones que cumplen en el plano del sistema y las relaciones internacionales.

Entre ellas cabe distinguir:

-El importante papel que desempeñan en el proceso de globalización como conductos de los flujos de inversión extranjera directa.

-Su influencia en el cambio de las modalidades de comercio internacional, desde un intercambio tradicional «inter industrias» $\mathrm{o}$ inter empresas a otro basado cada vez más en el comercio y las transacciones entre las empresas matrices y sus filiales en el exterior. Esto implica también problemas en la regulación y control de estas empresas. 
-Como acota De la Dehesa ${ }^{15}$ (De la Dehesa, 2000: 94), las EMN contribuyen a la difusión de la tecnología alrededor del mundo». «El 70\% de todos los pagos por derechos o tecnología que se realizan en el mundo se hace por multinacionales y sus filiales».

-Las EMN contribuyen a crear en los países en desarrollo un sector moderno que paga salarios relativamente más altos y genera empleos estables. Esto implica, a su vez, desafíos a los Estados en el sentido de impulsar políticas que tiendan a superar la segmentación y promover la cohesión social.

Un desarrollo reciente de las EMN es el del outsourcing o subcontratación de parte de los servicios o de los procesos de producción con empresas del grupo o cada vez en mayor medida, fuera del grupo multinacional. Estos procesos han sido criticados en lo que respecta a empresas subcontratistas que se instalan en países o regiones permisivas en aspectos laborales, tributarios o de protección del medio ambiente.

\section{LAS EMN EN EL SISTEMA INTERNACIONAL: ANÁLISIS DESDE DIVERSAS PERSPECTIVAS TEÓRICAS}

Aunque actualmente las EMN operan prácticamente en todo el mundo, incluyendo países en desarrollo y en muchos casos estos las buscan para que se instalen en su territorio, las visiones que se tienen

15 De la Dehesa, obra citada, p. 94. de las empresas transnacionales aún difieren según el punto de vista doctrinario o teórico que se tenga a su respecto, si bien no con toda la carga ideológica que fue propia de los años 1960.

Así, Karen Mingst (Mingst, 2001: 210) señala que para quienes son liberales en lo económico, las EMN son «la vanguardia del orden liberal» y representan el ideal liberal por excelencia de una economía mundial interdependiente. Estas empresas serían «las correas transmisoras de ideas, capital y crecimiento económico.

Según Mingst, para los «estatistas», que priorizan los objetivos políticos y económicos nacionales, las EMN pueden ser poderosos aliados cuando se ponen al servicio del Estado de origen pero agentes peligrosos cuando actúan en contra de sus intereses políticos.

La perspectiva o posición radical ofrece una crítica profunda a estas empresas, descartando la noción que las aprecia como instrumentos positivos de desarrollo económico y las ven como «un instrumento de explotación».

Así, la interdependencia que representan las EMN para los liberales y quienes privilegian el enfoque transnacional, es interpretada por los radicales como «imperialismo». Según esta concepción, en ese sistema, las decisiones "son tomadas en los centros económicos y financieros del mundo -Tokio, Nueva York, Berlín, Seul- mientras el cumplimiento de esas decisiones ocurre en plantas de los países en desarrollo", reflejando la desigualdad del sistema económico internacional. 
Robert Gilpin (Gilpin, 2000: 163) afirma que en los propios Estados Unidos, "muchos norteamericanos de todas las tendencias políticas creen que estas firmas gigantes plantean una amenaza seria al bienestar económico y social de los trabajadores americanos, a pequeños negocios y a las comunidades locales». Añade que «los receptores de inversión extranjera directa tienen una actitud muy ambigua hacia las EMN. Por un lado, se dan cuenta que las EMN traen capitales y tecnología valiosa para el país. Por otro lado, temen llegar a ser dominados y explotados por estas poderosas firmas. Nadie niega que las EMN han llegado a ser una característica esencial de la economía mundial y todos reconocen que los esfuerzos para devolver «el genio a la botella» no tendrán éxito. Entonces, se necesitan regulaciones internacionales para asegurar que tanto empresas como gobiernos se conduzcan de modo beneficioso para la economía mundial».

Así, Gilpin, especialista en economía política internacional de tendencia realista, comparte la posición de que se requieren normas internacionales para regular sus relaciones con los gobiernos.

Las EMN se configuran como actores dentro del sistema internacional, concebido como el conjunto de interacciones entre actores políticos internacionales bajo ciertas formas de control. No es esta la única visión. Como aludimos al comienzo, Octavio Ianni considera que existe "una sociedad global en formación», como el Estado-nación se ha debilitado ( «las naciones se volvieron demasiado pequeñas como unidades de comercio y demasiado grandes como unidades de administración» $)^{16}$ los movimientos de capital, tecnología, fuerza de trabajo, know how empresarial, etc. a nivel mundial, transforman las sociedades nacionales en dependencias de la sociedad global» (Ianni, 2004: pp. 26 y 61).

Es posible que la tendencia vaya en esa dirección, pero desde el punto de vista sistémico, aún no habría una sociedad global alrededor de la cual girarían los Estados o sociedades nacionales. A nuestro juicio, el enfoque de la sociedad global puede dar a ese concepto una densidad parecida a la que en 1977 Hedley Bull asignaba al concepto de «sociedad internacional», como un sistema en que las sociedades nacionales «mantienen y extienden un consenso sobre intereses y valores comunes que proveen el fundamento para reglas e instituciones comunes» y en el ambiente de una cultura cosmopolita (Bull, 2002). Aparentemente, se avanza en esa línea -lo que es deseable-, pero aún no se aprecian los valores comunes que trascienden los distintos intereses de los grandes actores y potencias y menos las consideraciones hacia los que tienen menos poder. Por otro lado, a pesar del poder de las grandes EMN, tampoco estaríamos en un sistema global regido por empresas apátridas, tal como algunos preconizaban con cierto entusiasmo en 1990.

16 Ianni, citando a Roberto Campos, «Além do cotidiano", 1985, p. 80. 
En los inicios del siglo XXI, las EMN no habrían transformado cualitativamente el sistema internacional y «el nuevo orden» más justo y estructurado está aún por establecerse. Sin embargo, su capacidad de adaptación a la economía globalizada las ha transformado en actores decisivos.

\section{RELACIONES ENTRE LAS EMN, EL ESTADO-NACIÓN Y OTROS ACTORES}

Como es natural, las relaciones entre las EMN y los Estados son frecuentes, y tanto con los Estados en que se ubica la empresa matriz como con aquellos en que se instalan filiales de cualquier tipo. Sin embargo, se discute si la creciente importancia de las EMN en la organización y manejo de la economía internacional constituye o no una transformación de los asuntos económicos y políticos globales.

Para unos, como el "globalista" Keiniche Ohmae (Ohmae, 1997), la respuesta es afirmativa y las EMN representarían «el triunfo de las fuerzas del mercado y la racionalidad económica sobre el anacronismo del Estado-nación y de una economía internacional políticamente fragmentada", en tanto otros las vinculan a la economía del país de la casa matriz.

En el momento actual, parecería que las EMN son verdaderos actores que caracterizan el sistema pero sin cambiar necesariamente su esencia. Coincidimos con Gilpin en que los mercados extranjeros son también mercados nacionales y las estrategias corporativas deben adaptarse a dichos mercados y a las políticas de los gobiernos que les sirven de anfitriones. Sin embargo, las opciones que tienen los Estados para fiscalizarlas se ven restringidas y existe una asimetría en la información que se posee, en beneficio de las empresas.

Las EMN y los Estados se envuelven en complejas relaciones de negociación y en este proceso han llegado a ser no solo organizaciones económicas sino políticas, con el potencial de influir en las políticas tanto del país de la casa matriz como del gobierno anfitrión. En esta materia no hay aún normas internacionales específicas sino diversos pronunciamientos de instituciones de la sociedad civil internacional que se oponen a propuestas de cartas de derechos de las EMN promovidas por las economías más desarrolladas y proponen otro tipo de normas de comportamiento. El tema discurre en varios ámbitos, como se verá a continuación.

- Acciones de los Estados. Los Estados más abiertos a la globalización, -sean desarrollados o en desarrollo-, promueven en sus políticas exteriores la extensión de mercados libres y apoyan a sus exportadores buscando suprimir las barreras proteccionistas. En este contexto se suceden acciones, ya sea formales o más bien informales, de apoyo a las EMN que tienen a esos Estados como país de origen. Es dable apreciar este tipo de actividades en todo tiempo y muy en particular cuando, por ejemplo, se discuten temas de integración 
regional y acuerdos de libre comercio en los que, según el poder negociador de los Estados, procuran obtener condiciones y clima favorables al desarrollo de sus empresas, y también en momentos de crisis o conflicto, cuando el Estado anfitrión imponga nuevas restricciones a la multinacional extranjera.

- Negociaciones. Naturalmente, en sus relaciones con los países anfitriones, las EMN deben cumplir con las normativas internas que rigen la inversión externa y la actividad empresarial en sus aspectos tributario, mercantil, laboral, ambiental, etc. Donde se advierten con más fuerza las negociaciones con el país anfitrión -que puede ser el Gobierno nacional u otra instancia, por ejemplo, un organismo descentralizado o una empresa estatal-, es al momento de concretar una inversión extranjera directa considerable, buscando las mejores condiciones que permita el medio local.

- Las EMN y la competitividad de las economías nacionales. Intereses nacionales y empresariales. Actualmente, aunque las EMN se han consolidado, tanto en los países desarrollados como en desarrollo, se manifiestan inquietudes sobre la relación entre los objetivos de las empresas y los objetivos nacionales.

Así, en el caso de los Estados Unidos, según David Korten ${ }^{17}$ (Korten

17 El tema se trata en Korten, David (2005): «Cuando las transnacionales gobiernan el mundo", p.125. La cita pertenece al informe de la Oficina de Evaluación Tecnológica del Congreso de los Estados Unidos
2005: 127), un informe de la oficina de Evaluación Tecnológica del Congreso de Estados Unidos expresa que «debido a que sobrepasan las fronteras nacionales, muchas multinacionales se preocupan menos de desarrollar objetivos nacionales que de buscar objetivos internos de la empresa: principalmente crecimiento, utilidades, tecnología patentada, alianzas estratégicas, retornos de inversiones y poder en el mercado... La economía estadounidense (o cualquier otra) no puede seguir siendo competitiva a menos que las multinacionales que venden y dirigen los negocios en Estados Unidos también contribuyan con su apoyo tecnológico y de investigación, empleo, habilidades manufactureras y recursos de capital». El informe señala que los intereses de todas las naciones van dirigidos a buenos empleos, un creciente estándar de vida, desarrollo tecnológico e industrial, seguridad de los derechos de empleados y consumidores y un ambiente de calidad a nivel interno y externo, y concluye que "comparados con aquellos de los países, los intereses de las multinacionales están mucho más orientados a la situación imperante y ligados a la oportunidad».

Korten agrega, generalizando, que a su juicio "las empresas japonesas se han orientado más hacia un interés nacional que las compañías estadouni-

(Multinational Corporations and the National Interest: Playing by different rules, Washington, D.C., U.S. Government Printing Office, 1993, pp. 1 a 4). 
denses, que han liderado el rechazo de los intereses nacionales a favor de un interés empresarial definido en término más restringidos, estando las empresas europeas en una posición intermedia». Sin embargo, claramente se tiende al transnacionalismo empresarial (Korten, 2005: 127).

- Lo nacional y lo subnacional: los «Estados-región». Otro tema que plantea principalmente Ohmae es la relación entre lo nacional y lo subnacional. Para este autor, «los consumidores cada vez desean más productos mejores y más baratos, vengan de donde vengan», agregando que los inversionistas no toman sus decisiones en un contexto de país sino regional o local, de los «Estadosregión» (Ohmae, 1997: pp. 19 y 20). Así, se invierte más bien en California que en Estados Unidos; Australia occidental tiene creciente vínculos con Singapur e Indonesia; las 27 regiones autónomas chinas gozan de gran discrecionalidad "para desarrollar su base industrial con la participación extranjera que puedan, $\mathrm{o}$ decidan, atraer» (Ohmae, 1997: pp. 148 y 160). Cabe comentar que siendo muy importante lo regional, y Ohmae apunta a un hecho real, el contexto político, jurídico, reglamentario y de regulación de los mercados continúan siendo fundamentalmente de carácter nacional.

- Producción, modelos, marcas y deslocalización. El informe de la UNCTAD correspondiente a 2004 apuntó a las «deslocalizaciones». De la Dehesa señala el fenómeno del outsourcing en que crecientemente se contratan servicios fuera del grupo multinacional, proceso que «llevado al extremo, conduce al nuevo concepto de empresas virtuales y a la desintegración y descolocación del proceso productivo» (De la Dehesa, 2002: 97). La empresa matriz se circunscribe al diseño, la tecnología, el control de calidad, la marca, el marketing, la publicidad, el financiamiento y la distribución, mientras que el resto se subcontrata fuera de la empresa en diversos países, para obtener piezas, partes, componentes y ensamblajes y servicios de administración, sistemas de auditoría, etc.

En un enfoque crítico, Eulalia Solé (Solé, 2003: 76), apunta a que en las últimas décadas los sistemas de producción han variado y el centro de gravedad se ha desplazado de la fabricación a las marcas y a los distribuidores, particularmente en la industria textil: «Las empresas creadoras de modelos con su propia marca subcontratan talleres de confección situados en países donde los costes de fabricación sean menores. Concepto que incluye salarios, fiscalidad, legislación laboral y reglamentación medioambiental. Exonerados de sus responsabilidades como patrones directos, eligen a los subcontratados, estipulan precios, calidad de la confección y plazos de entrega, y siempre esgrimen la posibilidad de trasladarse a otro lugar si no están satisfechos». Agrega que en Asia se han producido varias «oleadas» en busca de localizaciones cada vez más favorables.

- Normativa nacional e internacional. En lo relativo a la regulación de estos procesos, no es fácil establecer normas. Evidentemente, se aplica la 
normativa nacional, pero muchas veces los propios gobiernos atraen a las empresas subcontratistas ofreciéndoles condiciones favorables o no hay seguridad de que se aplique la legislación laboral. Las Naciones Unidas, la OIT y el UNICEF han elaborado informes sobre el trabajo de niños en maquilas e industrias textiles y la situación que afecta a los trabajadores no sindicalizados de países en desarrollo afecta también a los de países desarrollados que sí lo están. Un desarrollo de las dos últimas décadas es la adopción por las propias multinacionales -que son sensibles a las críticas de las organizaciones no gubernamentales de países desarrollados que pueden restarles clientes- de "códigos de conducta», algunos de ellos auditados por órganos externos. Sin duda, pueden ser un avance, pero también son objeto de críticas porque los "códigos» se aplican en algunos países y no en otros y los subcontratistas no los aplican. El criterio básico es que el "código" respete las normas de la OIT o la legislación nacional si esta es más favorable al trabajador.

- Diversas interacciones, foros y canales alternativos. Las EMN también se relacionan con otros actores internacionales, tanto del propio ámbito empresarial como la Cámara de Comercio Internacional (CCI) o con observadores ante organismos internacionales gubernamentales como la OMC o conferencias especializadas de las Naciones Unidas. En el caso de la CCI, organización empresarial fundada en 1919 que tiene representantes en más 100 países, son conocidas las funciones que cumple en materia de arbitraje internacional, pautas a seguir en negocios internacionales, competencia leal, armonización de terminología mercantil internacionale y un fenómeno de creciente actualidad, que es la lucha contra la corrupción que se produce con motivo de las transacciones comerciales internacionales. En esta materia se abordaron dos oleadas de corrupción en los años setenta y noventa, oportunidad en que se elaboraron reglas de conducta que naturalmente solo tienen efecto como incentivo a la autorregulación, pero también realiza gestiones ante organismos como la OCDE y la OMC para hacerles presentes sus puntos de vista (Malem Seña, 2000: 110).

Asimismo, se producen interacciones por medio de seminarios internacionales como el de Davos, abiertos a líderes mundiales ya sea gubernamentales, empresariales o del mundo académico y de las comunicaciones.

Las organizaciones de la sociedad civil que cuestionan la globalización o, más específicamente, aspectos que consideran particularmente injustos desde sus respectivos puntos de vista, también están formando redes de carácter mundial, que dirigen sus críticas y propuestas a los propios Estados, a organizaciones internacionales, a los organismos surgidos de Bretton Woods y también a las propias empresas multinacionales, lo que de alguna manera va densificando gradualmente el debate internacional sobre los flujos mundiales de intercambio. 
Cabe mencionar las reuniones del Foro Mundial Social realizadas a partir de 2001 en Porto Alegre con el lema de "Otro mundo es posible» y en cual se busca convergencia entre las posiciones críticas y el Foro Internacional sobre Globalización (FIG), que promueve alternativas a la globalización económica y busca aportar a la construcción «de una conciencia pública sobre la naturaleza y las consecuencias de la globalización corporativa». Estos «movimientos ciudadanos» no tienen una ideología oficial y carecen de un referente institucional único ${ }^{18}$.

Por su parte, Comercio Justo promueve un mercado alternativo que favorece la producción en condiciones

18 Foro Internacional sobre Globalización, Alternativas a la Globalización Económica (2003), Barcelona, Editorial Gedis, p. 13. En ese mismo documento, p. 18, la FIG expresa que «curiosamente, los movimientos ciudadanos buscan muchas de las cosas que los globalistas corporativos dicen ofrecer pero, de hecho, no consiguen dar participación democrática, economías de empresa que ofrezcan buenos empleos y respondan a las auténticas necesidades y preferencias de sus clientes, un medio ambiente sano y el término de la pobreza. Sin embargo, donde los globalistas corporativos buscan una economía global competitiva regida por megacorporaciones que no deben dar cuenta a nadie ni a a ni a nada, los movimientos ciudadanos buscan un sistema planetario de economías constituidas por empresas de propiedad local y responsables ante sus accionistas. Asimismo, trabajan por la justicia económica para todos, la cooperación internacional, el fomento de la diversidad cultural y unas sociedades sostenibles y sanas que otorguen más valor a la vida que al dinero». justas, comercio solidario, transmisión de información comercial a los productores, aprendizaje tecnológico y denuncia de las injustas relaciones económicas mundiales. Permite a los productores liberarse de las EMN y llegar a mercados de países en desarrollo sin intermediarios. Un ejemplo exitoso es la red de 250 mil productores cafetaleros reunidos en el Frente Solidario de Pequeños Cafetaleros de América Latina. También operan en artesanías, textiles y diversos rubros alimenticios (Solé, 2003: pp. 40 y 51).

- Intentos de regulación. Una materia en que el debate es especialmente arduo, en particular en tiempos de crisis financieras, es el de los flujos internacionales de capital, en especial de capitales golondrina que entran y salen intempestivamente de los países y dan lugar a la adopción de un conjunto de medidas para aminorar sus efectos negativos por las autoridades de Hacienda o Bancos Centrales de los países o propuestas más de fondo y de más larga discusión y plazo, como la tasa Tobin, un tributo de carácter internacional a los movimientos de fondos.

$\mathrm{Al}$ efecto, cabe mencionar los esfuerzos más amplios por mejorar la gobernabilidad de la globalización -el medio en que actúan las EMN- vinculando las variables políticas y económicas y los esfuerzos más específicos por regularlas y las normas propias del derecho internacional sobre la protección de personas jurídicas nacionales.

Entre los intentos de regulación multilateral, que en general no han 
fructificado, cabe mencionar la iniciativa de la OIT, de 1977, en virtud de la cual se aprobó la Declaración tripartita sobre los principios concernientes a las empresas multinacionales y la política social. Por otra parte, el Consejo Económico Social de las Naciones Unidas aprobó la resolución 1721 (LIII) por la que recomendó realizar estudios sobre la reglamentación internacional de estas empresas.

Los informes de 1973 y 1974, elaborados en el marco de las Naciones Unidas, condujeron a la creación de una Comisión de sociedades trasnacionales encargada de «formular, adoptar y aplicar un código internacional de conducta para las sociedades transnacionales». Por su parte, en 1980 la UNCTAD aprobó la Resolución 35-63 que propuso «un conjunto de principios y reglas equitativas convenidas a nivel multilateral, para el control de prácticas comerciales restrictivas».

Estas iniciativas no han fructificado. En el Foro de Davos en 1995, el entonces Secretario General de Naciones Unidas, Boutros Boutros-Ghali, consideró que dado el poder que tenían las EMN deberían estar relacionadas más directamente con las decisiones internacionales. Como contrapartida, en sus estrategias económicas y empresariales, deberían incluir las perspectivas de interés general y de bienestar colectivo. Para ello era preciso idear nuevas reglas y prácticas (Zarka, 1995: pp. 90 y 95$)$.

Igual suerte han corrido las propuestas surgidas de la OCDE, del mundo desarrollado y de las propias empresas que aspiran a no tener problemas de doble tributación, a agilizar los trámites y a que sus inversiones sean más seguras. Diversos grupos de la sociedad civil han tenido un éxito relativo «en alterar las agendas de las instituciones globales» mediante sus movilizaciones, como la realizada «contra el acuerdo Multilateral sobre Inversiones proponiendo una carta global de derechos para las EMN» (Held y McGrew, 2003: 79).

Esta propuesta, más conocida por su sigla en inglés MAI (Multilateral Investment Agreement) pretendió lograr un consenso mundial para liberalizar las inversiones extranjeras, definidas en forma muy amplia, más allá de las inversiones en la producción de bienes y servicios, e incluyendo múltiples tipos de inversiones, tales como inversiones en cartera, concesiones, inversiones inmobiliarias, propiedad intelectual, contratos de construcción, etc. (Mayorga, Morales y Polanco, 2004: 114). El principio fundamental del proyecto de la OCDE era la no discriminación del capital extranjero y entre las razones por las cuales no ha fructificado los gobiernos mencionan el temor de dar a los inversionistas un trato similar al de los Estados, mientras que los sindicatos y las organizaciones no gubernamentales insistían en incorporar cláusulas sobre estándares laborales de carácter internacional (Guardia, 2001: pp. 33 y 36$)$.

La OCDE, a la que Chile ha ingresado como miembro, promueve la cooperación entre los gobiernos con miras a favorecer la inversión extranjera directa 
y otros movimientos de capital y ha promovido opciones y mecanismos en pro de la liberalización de los flujos de inversión.

Además, existen numerosas convenciones de carácter bilateral que tienen por objeto dar seguridad jurídica a las inversiones. Naturalmente, en este tipo de acuerdos los países desarrollados tienen un fuerte poder negociador.

Siempre existe la posibilidad -y la preocupación- de que el aumento de tamaño de las empresas pueda afectar la competencia internacional y generar monopolios globales. De la Dehesa señala que eso no sucederá porque en los países existirían normas y autoridades que lo impedirían, pero advierte «que en un mundo globalizado no va a ser suficiente con las instituciones nacionales de defensa de la competencia» (De la Dehesa, 2002: 103). Por de pronto, en la Unión Europea existen una Dirección General y un Comisario de la Competencia y en los Estados Unidos se ha actuado contra Microsoft. Además, en distintos ámbitos surgen iniciativas relacionadas con la coordinación de las iniciativas nacionales, la creación de mecanismos en áreas de integración subregional, la celebración de acuerdos multilaterales y la creación de un mecanismo supranacional. Así, se ha sugerido que en el marco de la OMC se suscriba un convenio sobre medidas antimonopolios en el comercio (TRAMS).

El derecho internacional contempla la institución de la protección diplomática de personas jurídicas -con determi- nados requisitos- y estimula la seguridad de las inversiones. En todo caso, la tendencia actual se manifiesta en la preferencia «tanto de los Estados de los inversionistas como de los receptores de inversión extranjera, por someter las controversias que surjan, más que a los tribunales del Estado donde se ha efectuado la inversión, a procedimientos arbitrales convenidos conjuntamente, como es el caso de la Convención sobre Arreglos de Diferencias Relativas a Inversiones entre Estados y Nacionales de otros Estados (CIADI), suscrita en Washington en 1965» (Vargas Carreño, 2007: 510). Dentro del mecanismo arbitral de dicha convención se identifican dos elementos, los referidos a la jurisdicción de sus tribunales y los propios del procedimiento de arbitraje institucional y dentro de estos a su naturaleza consensual (Mayorga, Morales y Polanco, 2004: 183).

En el debate actual, hay quienes califican la actual globalización de «depredadora»y advierten sobre sus efectos acumulativos adversos en el bienestar humano, que exigiría «un nuevo equilibrio a escala global entre fines y medios en las relaciones trilaterales entre el Estado, el pueblo y el capital», y advierten que las políticas públicas estarían condicionadas al capital global» (Falk, 2002: 3). Según esta posición, solo una variedad de presiones transnacionales sobre los Estados del mundo "podría alterar la ecuación política hasta el punto que el Estado pudiera recuperar su autonomía respecto a la economía mundial». 


\section{LAS EMN Y SU RELACIÓN CON LOS ESTADOS EN América latina. El caso DE CHILE}

Tanto en el mundo en desarrollo en general como en América Latina las EMN viven en medio de la tensión entre su pretensión de consolidación y autonomía para llevar adelante sus intereses empresariales articulando actividades en distintas economías, por una parte, y las interpelaciones que les formulan a la vez el Estado de su casa matriz y aquellos en que operan sus filiales sobre sus responsabilidades relacionadas con el interés general de las respectivas sociedades, por la otra.

\section{Las EMN como actores politicos y agentes económicos}

No es este un tema que se haya estudiado a fondo. Naturalmente, todos los países tienen regulaciones que deben cumplir todas las empresas que operan y se registran en ellos, formen o no parte de conglomerados multinacionales, y lo mismo sucede con la inversión extranjera, que en su mayor parte se canaliza a través de este tipo de empresas. También hay normas aplicables a las fusiones o joint ventures entre empresas extranjeras y capital nacional.

\section{América Latina: competencia, estrategias de desarrollo e internacionalización}

En la medida en que América Latina se ha incorporado a la globalización se han desarrollado instituciones y normas sobre la libre competencia-concebida como la situación «en la que dos o más agentes económicos ofrecen bienes o servicios similares intentando atraerse a los consumidores»-y las prácticas anticompetitivas. Se trata de proteger el proceso de competencia, fomentar la eficiencia económica y proteger el bienestar de los consumidores. Así, México adquirió una importante experiencia en la materia a través de su participación en el NAFTA (TLCAN, en su sigla en castellano) y en los trabajos -que no fructificaron- del ALCA (Witker, 2003:pp. 4 y 12).

El tipo de intervención -más o menos abierta u oficiosa- de los gobiernos para acompañar la acción económica de sus empresas multinacionales es un punto que va a estar presente en el futuro, en la medida en que las interacciones económicas sean más fluidas y abundantes. Dentro de las formulaciones de política exterior de los países de economía abierta, entre los que se cuentan tanto los Estados Unidos como Europa y también Chile, está la de apoyar el libre comercio y el multilateralismo, diferenciándose -según ha quedado claro en las Rondas de la OMC- en los puntos en que hay intereses no convergentes, como en lo relativo al proteccionismo de los países desarrollados en el sector agrícola. 
Una posición más ligada a los conceptos de desarrollo nacional y desarrollo latinoamericano es la del argentino Aldo Ferrer en su análisis de la globalización, Argentina, Brasil y el Mercosur (Ferrer, 2006). Para este autor, la globalización de la economía mundial se manifiesta en cuatro terrenos principales: el comercio internacional, las corporaciones transnacionales, las corrientes financieras y los marcos regulatorios, mencionando entre estos últimos las reducciones arancelarias, la formación de la OMC con «normas comunes y más liberales para el tratamiento de las inversiones privadas directas y los servicios; y más rigurosas para la protección de la propiedad intelectual» (Ferrer, 2006:16). América Latina ha ido perdiendo posiciones en el mercado mundial y critica lo que llama "visión fundamentalista de la globalización» que sugiere que el dilema del desarrollo en un mundo global ha desaparecido por cuanto «las decisiones principales no las adoptan hoy las sociedades y sus Estados, sino los agentes transnacionales». En este contexto, "las condiciones vigentes de la competencia global obligan el estado a facilitar la navegación de las empresas en el mercado sin fronteras» (Ferrer, 2006: pp. 24 y 25).

Frente a lo anterior, Ferrer destaca mecanismos como el Mercosur que a pesar de sus problemas ha permitido incrementar el comercio intrazonal y señala que «la dimensión endógena es fundamental. Al fin y al cabo en el Mercosur el mercado interno es el destino del $90 \%$ de la producción doméstica y genera otro tanto del empleo». Refiriéndose fundamentalmente a Argentina y Brasil dice que «disolver este paso decisivo de la dimensión endógena es incompatible con el desarrollo de estos países» y agrega que «la consolidación de una visión autocentrada del desarrollo en un mundo global es condición necesaria de estrategias nacionales realistas", que consigan la inserción internacional como instrumento de movilización del potencial de recursos internos y desarrollo humano sustentable. En este contexto, señala que «Brasil es, tradicionalmente, más industrialista que Argentina y más proteccionista de su mercado interno" (Ferrer, 2006, pp. 74 a 78$)$.

Este análisis reflejaría, entre otras cosas, la situación especial de un país de las características, grado de industrialización y tamaño de mercado de Brasil. Por lo demás, el tema de reindustrializar, tecnificar y plantearse distintas modalidades de inserción en las corrientes globalizadoras estuvo presente en las elecciones presidenciales argentinas de 2007.

Dentro de la concepción amplia de regionalismo abierto, y como veremos en el párrafo siguiente, en la región coexisten diversos esquemas de integración con el proceso de globalización. Entre ellos cabe mencionar la ALADI, la CARICOM, el Mercado Común Centroamericano y la Comunidad Andina de Naciones -a la que Chile se acaba de reintegrar como miembro asociado-, así como otros más recientes 
como el Mercosur o a nivel de propuesta, como la Comunidad Sudamericana de Naciones.

A lo anterior se agregan diversas estrategias de ajuste, liberalización económica, atracción de inversiones y esquemas bilaterales de libre comercio, camino en el que Chile de algún modo se adelantó y ahora es seguido por países como Perú y Colombia.

En su análisis de la IED en el momento actual, el Secretario Ejecutivo de la CEPAL expresa que «el desafío está en que los países mejoren su atractivo con reglas del juego claras, infraestructura, recursos y competitividad, además de dar más importancia a los organismos de promoción de inversiones, vinculándolos con la estrategia de desarrollo» ${ }^{19}$.

La CEPAL justamente ha expresado (CEPAL, 2006) que para atraer IED de calidad es preciso aplicar políticas activas e integradas que formen parte de la estrategia nacional de desarrollo. «Estas enseñanzas se desprenden de las prácticas de políticas vigentes en los países europeos y asiáticos que han tenido mayor éxito y que ponen en evidencia el contraste existente con las políticas más pasivas e inconexas que se aplican en este ámbito en América Latina y el Caribe».

19 El Mercurio, 4 de mayo de 2007, «Declaraciones del Secretario Ejecutivo de la CEPAL, José Luis Machinea».
Globalización y esquemas

regionales de integración

Un punto aplicable a América Latina en general y a Chile en particular es el de la relación entre el regionalismo y los esquemas regionales de integración con los mercados mundiales y las disposiciones de la OMC a ese nivel. Como ya lo hemos señalado en otras oportunidades, los procesos de globalización económica y de regionalización tienen lugar en forma simultánea y, en una perspectiva de regionalismo abierto, los esquemas regionales de cooperación refuerzan la integración global. Además, el conocimiento mutuo que genera entre sus miembros un TLC o una asociación menos institucionalizada como el APEC acrecienta las oportunidades de comercio y de inversión (Allard, 2003).

Así, se señala, que a pesar de que los países liberalizan unilateralmente su comercio, los esquemas regionales de integración se justifican cuando los mercados son incompletos o imperfectos- no totalmente abiertos y estables- $y$ "frente a economías de escala, lo que de otra forma podría ser una desviación de comercio ineficiente, puede convertirse en una desviación de comercio reductora de costos e incrementadora del bienestar» (Ffrench. Davis, 2001: pp. 48 y 49).

Desde el punto de vista de las EMNy de la IED, el acceso a un mercado de mayor tamaño indudablemente las favorece. En su estudio sobre la integración, el académico guatemalteco 
Guerra-Borges señala que muchas empresas que antes intentaron «una estrategia de globalización de sus operaciones centralizando en la empresa matriz la conducción de todas las operaciones, han concluido que su mejor opción es regionalizar sus actividades de producción y distribución. Pese a las predicciones de los profetas de la globalización sobre la estandarización de los productos en todos los mercados, han persistido tenazmente los requerimientos específicos de la demanda local» (Guerra-Borges, 2002: 191).

Un caso especial, por su alcance continental, fue el intento de constituir el $\mathrm{ALCA}^{20}$.

\section{Inversión productiva y flujos financieros}

A pesar de la decisiva importancia de la IED, gran parte $(90 \%)$ de la inversión a nivel mundial es nacional. En cuanto al contenido de la IED, Ffrench-Davis destaca la importancia de atraerla «en las áreas más relevantes

20 Los intentos no fructificaron principalmente por diferencias de intereses comerciales, entre ellas lo relativo al acceso de productos agrícolas a Estados Unidos. Aparte de lo anterior, hay posiciones radicales que aluden a la formación de bloques como «el equivalente funcional del imperialismo colonial». Véase SaxeFernández, John, James Petras, Henry Veltmeyer y Omar Núñez (2004), Globalización, Imperialismo y Clase Social, Buenos Aires, Grupo Editorial Lumen Humanitas, p. 101. para la innovación y que llegue a crear nueva capacidad productiva, en vez de concentrarse en la compra de lo ya existente». Este tipo de inversión «suele representar flujos estables», en tanto señala el carácter «dinámico y volátil» de la globalización financiera (FrenchDavis, 2007: pp. 35 y 36)

Sabemos que en el mercado mundial los flujos financieros tienen gran autonomía «aun en aquellas economías que los provocan». Enfrentadas «las economías latinoamericanas a la volatibilidad de fondos, de lo que se trata es de privilegiar las inversiones a largo plazo». El tema tiene muchas aristas, Héctor Vega refuerza la idea de que la entrada de capitales en América Latina «representa la compra de empresas en pleno funcionamiento, afectando al empleo a través de la reestructuración de personal» (Vega, 2001: 17).

Es fundamental aumentar el capital físico y las fuentes de empleo. Sin embargo, como se ha dicho, a nivel internacional la realidad apunta a una tendencia a adquirir unidades económicas en funcionamiento y a establecer diversas formas de asociación, lo que también es válido para las "translatinas", y los Estados son llamados a buscar solución a los problemas inherentes.

\section{Casos especificos}

A partir de 2006 hemos sido testigos de situaciones complejas, como la originada por las medidas adoptadas por 
el gobierno de Bolivia de acuerdo con su nueva política de control energético y de los hidrocarburos, que afectaron las inversiones y operaciones en ese país de la empresa brasileña PETROBRAS -y otras-y las negociaciones sobre precios y otros rubros. El caso sirve para ilustrar el tema de la interacción de la política y la economía, por cuanto se sucedieron contactos, visitas y entrevistas a nivel de Presidentes y de ministros en que se combinaron la acción gobierno local-empresa externa y las relaciones gobierno-gobierno. En este contexto, la intervención del gobierno brasileño obedeció a su preocupación por las EMN basadas en su propio país y la aceptación de las nuevas condiciones se debió al interés por mantener vínculos con Bolivia en el ámbito de una comunidad sudamericana.

Por otra parte, en un país como Chile, con un sistema económico abierto, bajos aranceles aduaneros y una vasta red de acuerdos económicos, particularmente en la forma de acuerdos de complementación económica en el marco de la ALADI y de tratados y asociaciones de libre comercio, incluso con las principales potencias económicas del mundo, las actividades de las empresas multinacionales son abundantes, y complejas, en especial si se considera que actualmente el $65 \%$ del PGB corresponde al comercio internacional (exportaciones e importaciones).

Otro caso se relaciona con la masiva inversión de España en la región en los años noventa, que se ha estabilizado tras algunos altibajos y se ha ampliado a diversos países de norte, centro y Sudamérica, aunque en montos muy diferentes. Geográficamente, se orienta a tres grupos: México, Argentina, Chile y Brasil absorben el $84 \%$ de los flujos. Le siguen Colombia, Perú, Uruguay y Venezuela con un $13 \%$, y después, un heterogéneo grupo en que se destacan Guatemala y República Dominicana (Arahuetes y García, 2007: 37). También en este caso se pueden apreciar paralelismos en la inversión económica, los contactos políticos a nivel bilateral y multilateral y la interacción entre Estados y empresas.

\section{Estrategias de internacionalización de las empresas}

Aunque no hay necesariamente un patrón único, al igual que lo sucedido en los países desarrollados en la internacionalización de las empresas latinoamericanas pueden observarse diversas fases, desde una instancia inicial en que priman factores de especificidad del producto (exportación y licencias o marcas), para pasar luego a la concentración de empresas (joint ventures, empresa, conglomerado) y concluir con la materialización de la inversión extranjera directa (Sierralta, 2002: 65).

\section{El caso de Chile: la economía abierta y la IED}

En este contexto, como lo señala con agudeza Manuel Castells, el modelo chileno implica mantener una 
economía abierta a la globalización de los mercados, contrarrestando las tendencias proteccionistas de los países desarrollados y asiáticos: "Chile gana en las situaciones de apertura máxima. Tal vez sea (junto con Hong Kong) el único país del que objetivamente más favorece un régimen liberal en términos de comercio internacional (Estados Unidos es cada vez más proteccionista en la práctica)»(Castells, 2006: 89). Sin duda, se trata de una situación real que hay que preservar ${ }^{21}$.

La regulación de las EMN debe tener en cuenta esta circunstancia propia de nuestro país, además de la normativa nacional propiamente dicha sobre inversiones y regulación del comercio y de la competencia, incluso adoptando los acuerdos de la OMC sobre materias tales como la valoración aduanera de las mercancías, la protección de la propiedad intelectual, medidas de frontera, normas de origen, etc.

Muchos de estos temas surgieron durante las negociaciones de los tratados de libre comercio con Estados Unidos, la Unión Europea, Corea, etc., en las que no hay duda de que los gobiernos

21 El reconocimiento que hace Castells a la competitividad de la economía chilena en condiciones de una amplia liberalización del comercio es bastante compartido en diversos círculos académicos, empresariales y gubernamentales, según pudo apreciar el autor del presente artículo mientras se desempeñó como Director Nacional de Aduanas entre 2002 y 2005 y le correspondió participar en diversas reuniones y foros de carácter internacional en temas de comercio internacional y aduaneros. de estos asociados comerciales tuvieron en cuenta tanto sus propios intereses nacionales como los de las empresas con casas matrices en sus países de origen que operaban o tenían perspectivas de operar en nuestro país. Lo mismo se aplica en el caso de las asociaciones empresariales chilenas que actuaban en interacción con la DIRECON y los negociadores.

Por lo demás, junto con liberalizar el comercio los TLC crean clima apropiado para profundizar las relaciones. Así se desprende, por ejemplo, del análisis que hace el Ministro de Relaciones Exteriores de Chile de la firma del TLC con Japón, en la perspectiva de una sociedad de «mediano y largo plazo $»^{22}$.

\section{Interacciones entre Estado y empresas}

En el caso de Chile estas interacciones son variadas:

a) Los objetivos de política exterior que favorecen el libre comercio y la plena inserción en el mundo incluyen acciones en los planos unilateral, bilateral y multilateral y la participación

22 En un artículo de opinión, "Chile y Japón, una relación promisoria» (El Mercurio, Santiago, 7 de septiembre de 2007), el Canciller Alejandro Foxley señala que es importante "para el sector privado tanto de Chile como de Japón, mantener la perspectiva de largo plazo", esto es, hacia dónde va un país y las condiciones de estabilidad y confiabilidad para hacer inversiones de envergadura y ser socios en el mediano y largo plazo. 
en la OMC y otras instancias, en la búsqueda de reglas estables que tengan en cuenta los distintos intereses, incluyendo por cierto aquellos de los países en desarrollo.

b) Durante las negociaciones de los Tratados de Libre Comercio cuya conducción ha estado a cargo del Ministerio de Relaciones Exteriores y la DIRECON, los empresarios han tenido un rol de consulta permanente. Una vez suscritos los tratados, se ha procurado también que sirvan de marco para inversiones recíprocas, esfuerzos que se están haciendo, por ejemplo, en los casos de Corea y China. En este contexto, la participación de Chile en foros como el APEC ha servido para crear las corrientes de conocimiento mutuo y confianza necesarios.

c) Interacciones Estado-empresas para promover las exportaciones y alentar inversiones en el país, por diversas vías incluyendo nuestro servicio exterior, Pro Chile, etc., lo que requiere de estrategias sostenidas ${ }^{23}$.

23 En un artículo de opinión el Embajador de Chile en los Estados Unidos sostiene que para optimizar las inversiones norteamericanas se han realizado encuentros en diversos estados, por distintas materias», en energía (Nueva York); aspectos legales de la inversión extranjera (Washington DC); concesiones y obras públicas (Chicago)» y otros. Señala el Embajador que en ellos «se ha contado con la propia presidenta, ministros, expertos, profesionales y empresarios de ambos países y se ha cumplido largamente el objetivo de mostrar una economía en buen estado, con oportunidades, evidenciado que otros han sustituido a los inversionistas tradi-

\section{Disposiciones más vinculadas a la} IED y las EMN

Al respecto cabe mencionar:

a) en el caso de las inversiones, los dos regímenes más utilizados en Chile son el DL 600 sobre inversiones extranjeras y el denominado Capítulo XIV de regulaciones del Banco Central. Sus disposiciones regulan tanto la inversión de capital como la repatriación de la inversión y sus utilidades. La vía del capítulo XIV se realiza a través de una entidad que forma parte del Mercado Cambiario Formal. En el caso del DL 600 el inversionista celebra un contrato con el Estado de Chile, declarando en su solicitud el propósito de la inversión.

b) en lo que respecta a la libre competencia, las normas aplicables que apuntan a promover y asegurar la libre competencia en los mercados están contenidas en el Decreto Ley $\mathrm{N}^{\circ} 211$ y modificaciones posteriores. La Ley establece, en general, que la libre competencia es un bien jurídico amplio que debe ser protegido. La institucionalidad comprende el Tribunal de Defensa de la Libre Competencia, órgano jurisdiccional e independiente, sujeto a la superintendencia de la Corte Suprema y la Fiscalía Nacional Económica, servicio público descentralizado que instruye las

cionales e intentando llegar a grupos y regiones en Estados Unidos que, generalmente, no han realizado mayores actividades con o en Chile» (Mariano Fernández Amunátegui, "Chile-EEUU: Balance de una Relación", El Mercurio de Santiago, 12 de septiembre de 2007). 
investigaciones necesarias para comprobar las infracciones al DL 211 y hacer requerimientos al tribunal.

c) las consideraciones ambientales, reguladas por diversas disposiciones de la Constitución Política, la Ley de Bases Generales, que establece el Sistema de Evaluación de Impacto Ambiental, y la Comisión Nacional del Medio Ambiente (CONAMA), cuya dirección superior corresponde a su presidente que tiene el rango de Ministro de Estado.

\section{Mejoramiento de la inserción} internacional, de la producción y de las condiciones de vida

Ha existido en Chile una discusión recurrente acerca de si se ha mantenido o superado «el modelo neoliberal». En una publicación reciente, Gonzalo Martner (Martner, 2007: 44) revisa el decálogo del denominado "Consenso de Washington» de comienzos de los años noventa y afirma que no corresponde caracterizarlo como "necesariamente neoliberal», por «practicar la disciplina presupuestaria», «integrar la economía nacional a la economía mundial en los ámbitos financiero, comercial y de inversión externa", "otorgar prioridad presupuestaria al gasto en salud y educación y a la infraestructura» y "garantizar derechos de propiedad, mientras se someta al interés general en materias tributarias, sociales, urbanoterritoriales, sanitarias y ambientales». Sí lo serían las políticas tendientes a «reformas tributarias que disminuyan la progresividad del impuesto» $\mathrm{y}$ "privatizaciones y desregulaciones indiscriminadas», cosa que no ha ocurrido. Así, las políticas sociales, previsionales y otras de protección social superarían dicho modelo.

En palabras de Held y McGrew, el Consenso de Washington, favorable a la liberalización, la desregulación y el libre comercio, «tendrá que dar paso al más reciente "consenso de Monterrey» sobre financiación del desarrollo (a partir de la Conferencia de las Naciones Unidas sobre Financiación del Desarrollo, realizada en Monterrey en 2002). Debe darse prioridad a la seguridad humana y al desarrollo humano por encima de las exigencias de los mercados globales. Del mismo modo que la conferencia de Bretton Woods creó el marco de un orden económico mundial abierto que conducía a la socialdemocracia, a juicio de numerosos globalistas no debería estar fuera de la imaginación política contemporánea construir un «New Deal» mundial a fin de gobernar la globalización de modo que promueva un orden mundial más justo, humano y pacífico (Held y McGrew, 2003: 99).

Lo anterior señala la necesidad impuesta por la propia realidad de una interacción de las variables políticas y de las propiamente económicas, que permita un clima adecuado para las inversiones y, al mismo tiempo, el interés nacional de promover la producción y el mejoramiento de las condiciones de vida de toda la población. 


\section{Constantes, Desafíos Y SUGERENCIAS}

Finalmente, mencionaremos algunas constantes, principios y lineamientos que se destacan de manera especial desde la perspectiva de los países en desarrollo de América Latina y de Chile:

a) El espacio y su importante papel en el mundo actual. Las EMN tienen un espacio amplio -y creciente- en el mundo globalizado de los inicios del siglo XXI y, en general, en el mundo en desarrollo que requiere de IED. Ello sucede en países que han crecido de manera espectacular como China y también, naturalmente, en América Latina, región que se desarrolla con apertura al capital externo, principalmente proveniente del mundo desarrollado y en mucha menor medida, de los propios países en desarrollo y de América Latina.

b) Chile, inserción internacional y desafíos. En el caso específico de Chile, su propia inserción internacional implica una intensa actividad en el país de EMN de países desarrollados, de países en desarrollo y de las propias empresas chilenas que invierten en el exterior, y las correspondientes corrientes de inversión. Esto implica apertura económica, reglas del juego claras y expeditas para las empresas nacionales y extranjeras, equilibrio fiscal, comercio internacional diversificado, transparencia en la gestión pública y políticas adecuadas que aseguren el óptimo aprovechamiento de esas inversiones en beneficio de su economía y su población. A Chile le va bien en la globalización, pero lo mismo ocurre con otros países en desarrollo, y para mantener la competitividad y mejorar la distribución del ingreso debe enfrentar retos en el desarrollo de las pyme, la calidad de la educación, la capacidad científico-tecnológica y de innovación y otras materias, en tanto se abre el debate sobre los niveles de competencia y concentración en ciertos rubros y la estrategia de desarrollo.

c) Interacción entre la política y la economía. La interacción que existe entre la política y la economía se manifiesta en la atención que los países ponen a la fluidez en el funcionamiento de sus empresas en terceros países y en la acción de los gobiernos por asegurar la transparencia de sus operaciones y los beneficios para el Estado y la sociedad receptora. La realidad parece indicar que Estados y empresas se necesitan mutuamente y que los gobiernos están dispuestos a reconocer beneficios razonables en la medida en que ello les permita llevar adelante sus políticas de desarrollo, empleo, avance tecnológico y promoción de las exportaciones.

d) Las posiciones teóricas sobre las $E M N$. Las posiciones más radicales, las de globalismo liberal a ultranza y las de aquellos que consideran que las EMN son simplemente empresas nacionales que compiten a escala internacional representando los intereses de los Estados en que se encuentra su casa matriz, parecen simplificar un fenómeno de suyo complejo.

e) Información y control. Aunque legalmente las EMN tienen domicilio 
en el país de la casa matriz y ordinariamente en los países de cada una de sus filiales, y que en aspectos como los tributarios prima el principio de que en cada país se tributa por las actividades realizadas en ellos, en la práctica ni unos ni otros Estados cuentan con toda la información sobre las actividades que llevan a cabo a nivel internacional de modo de poder ejercer un control cabal sobre ellas, lo que implica un desafío abierto.

f) Decisiones de las EMN y repercusiones en los Estados. Mientras que las EMN pueden tomar decisiones rápidas para trasladar sus operaciones, o partes de ellas, a otro país, reorientar sus flujos de inversión, operar en países cuya legislación laboral es más flexible o ajustar sus actividades de modo de tributar en condiciones más favorables, los Estados pueden verse enfrentados a situaciones en que sus ingresos son inferiores a los proyectados y de todos modos tienen que asumir las consecuencias de las decisiones de las empresas en materia de empleo y otras, así como sus responsabilidades en materia de seguridad social. Muchas veces se habla de ineficiencia del Estado -y cuando existe hay que atacarla- pero también hay situaciones en que los Estados deben hacerse responsables de las consecuencias de decisiones que escapan a su control.

g) El mercado mundial y la reglamentación nacional. Al parecer habría un desajuste propio de la actual fase globalizadora de la economía en que coexisten las fuerzas que generan la expansión de un mercado económico único -en que las EMN se mueven con fluidez como conductos de la inversión y del conocimiento-, con las fuerzas de nivel regional, nacional y local que intentan atraer y regular dichos flujos y empresas en espacios limitados, conforme a sus intereses nacionales y políticas y a los requerimientos y necesidades de su población. Diversas voces reclaman una arquitectura global con valores universalmente compartidos, lo que aún no se aprecia en la realidad. De hecho, en lo relativo a la regulación de la IED y las EMN se advierte un statu quo en que ni los Gobiernos, ni las empresas ni las organizaciones de la sociedad civil internacional pueden imponer sus puntos de vista, pero sí vetar las propuestas de los demás. Con todo, hay creciente conciencia de la necesidad de establecer nuevas reglas en el proceso de globalización.

b) Relaciones entre el Estado y las empresas, y sentido de la "protección». La realidad indica que habrá creciente interacción entre las EMN y el Estado anfitrión en el marco del proceso de atracción de inversiones, mientras que la acción "protectora» del Estado de origen tenderá a concentrarse o restringirse a la aplicación de normas -como las surgidas de los acuerdos de libre comercio o de la normativa multilateral-o de prácticas de no discriminación arbitraria. Existen márgenes para que, sin llegar a prácticas proteccionistas o que vulneren normas de la OMC, los Estados puedan favorecer las ventajas competitivas de sus empresas.

i) Concentración y libre competencia. La concurrencia de empresas nacionales y multinacionales en las distintas 
economías y mercados, la frecuencia de las adquisiciones de empresas ya existentes en el mismo sector o sectores relacionados y el consiguiente proceso de concentración, requiere de acciones positivas que estimulen y preserven la libre competencia.

j) Propuestas de regulación. Si bien no hay un estatuto que regule la IED y las EMN de modo consensuado entre los distintos intereses públicos y privados en juego, existe creciente información al respecto y un debate internacional a través de medios de comunicación y foros diversos que permiten detectar situaciones abusivas e ir avanzando hacia cierto consenso en torno a determinadas conductas éticas. Iniciativas como la ya mencionada tasa Tobin y otras orientadas a crear fondos para paliar los efectos negativos de la globalización en algunas sociedades y grupos humanos, no han logrado avances significativos.

k) Compatibilizar apertura global con politicas nacionales. En el caso específico de la inversión y las EMN, una actitud positiva y proactiva frente a la globalización como la que Chile ha asumido, sin duda requiere de flujos de inversión y de la presencia de empresas extranjeras en el país y chilenas en el exterior, en diversos sectores en que se compite también con otros países en desarrollo. Conocemos las dificultades -no exclusivas de los países en desarrollo- con que tropiezan los Estados para tener la información necesaria y poder controlar el cumplimiento de la normativa nacional en materia de fun- cionamiento legal, normas laborales e impositivas, etc. y generar un ambiente favorable a su desarrollo y a los intereses de su población

l) Acción público-privada de acompañamiento de la inversión y toma de decisiones a nivel nacional. Sin llegar a tener lo que se denomina una "política industrial»-como la que tradicionalmente se atribuía, por ejemplo, a Japón- los países latinoamericanos y Chile pueden perfeccionar diversos mecanismos de promoción, fomento y fiscalización que, compatibles con los compromisos internacionales vía TLC y normativa como la de la OMC, privilegien un acompañamiento activo del Estado a las empresas y negocios con sede más permanente en el país y a aquellas en que las principales decisiones se toman en su suelo. Chile posee un alto grado de internacionalización de su economía, lo que de algún modo responde al estilo de desarrollo predominante en las últimas décadas, y también a las características de un país con bastante cohesión social y grado de gobernabilidad y un mercado y población relativamente reducidos. Esta situación difiere, por ejemplo, de la de países como Brasil y otros que tienen grandes mercados, lo que también se refleja en sus decisiones de política económica y en su estrategia de desarrollo e inversión.

m) Combinación de mecanismos bilaterales y multilaterales. Naturalmente, no se trata de que un país en desarrollo como Chile ponga unilateralmente trabas a la inversión extranjera que solo 
pueden significarle perjuicios o desvío de capitales sino que, por el contrario, de mantener una economía abierta y aprovechar los TLC que ha suscrito y a la vez actuar la vía multilateral, para aumentar los flujos de inversión y la apertura de los mercados de los países desarrollados.

n) ¿Hacia un régimen internacional? La mayor difusión en el futuro de áreas o sectores sujetos a «regímenes internacionales», según la expresión de Stephen Krasner que ha logrado ser generalmente aceptada por economistas, juristas y cientistas políticos, facilitará esta interacción entre actores «mixtos» como son los Estados y las EMN de manera de asegurar el respeto a la sociedad receptora de la multinacional y de la inversión y a la acción empresarial ejercida dentro de marcos legales y responsables.

o) Ordenamiento de la actividad trasnacional. La creciente interacción de los sectores público y privado -con la cooperación del mundo académico- en diversos foros, podría ser el camino para que nuevas propuestas de ordenamiento de la actividad empresarial transnacional puedan surgir en conjunto y con una mirada global, más allá de los intereses inmediatos de los respectivos actores. No hay duda de que acciones de este tipo son preferibles al juego de presiones, retiro repentino de capitales, boicots a determinados productos, represalias, amenaza de expropiaciones o medidas de fuerza no amparadas en normas legales o consensuadas y demas mecanismos que tienden a proliferar cuando no hay criterios globalmente concordados.

\section{BibLIOGRAFÍA}

Allard, Raúl (2003), «Política Internacional, regionalismo y el rol de las aduanas», en Revista de Derecho, Valparaíso, PUCV.

Allard, Raúl (2004), «Globalización, rol del Estado y relaciones Internacionales en el realismo de Robert Gilpin», en Revista Estudios Internacionales, $N^{\circ} 146$, Santiago, Instituto de Estudios Internacionales de la Universidad de Chile.

Arahuetes, Alfredo y Aurora García, (2007), ¿Qué ha sucedido con la Inversión Extranjera Directa (IED) de las empresas españolas en América Latina tras el boom de los años noventa y la incertidumbre de los primeros años 2000?, Documento de Trabajo N³5/2007, Real Instituto Elcano, Madrid (mimeógrafo).

Alkins, Pope(1977), Latin America in the international political system, Londres, The Free Press.

Attiná, Fulvio (2001), El sistema político global, Barcelona, Paidós.

Beck, Ullrich (1998), ¿¿ué es la globalización?, Barcelona, Paidós.

Bull, Hedley( 2002), The anarchical society. A study of order in world politics, Nueva York, Columbia University Press.

Campos, Roberto (1985), Alem do cotidano, Río de Janeiro, Editora Record.

Castells, Manuel (2006), Globalización, desarrollo y democracia: Chile en el contexto mundial, Santiago, Fondo de Cultura Económica.

CEPAL (1994), Regionalismo abierto en América Latina y el Caribe. La integración al servicio de la transformación productiva con equidad, Santiago.

CEPAL (2006), La inversión extranjera en América Latina y el Caribe, Santiago, Naciones Unidas/CEPAL.

Chunovsky, Daniel y Andrés Lopez (1999), «Inversión extranjera directa y empresas 
multinacionales de países en desarrollo. Tendencias y marco conceptual», en Chudnovsky, Daniel, Bernardo Kosacoff y Andrés Lopez (1999), Las multinacionales latinoamericanas: sus estrategias en un mundo globalizado, Buenos Aires, Fondo de Cultura Económica.

De la Dehesa (2002), Comprender la globalización, Madrid, Alianza Editorial.

Dunning, John (1988), Explaining international production, Londres, Uniwin Hyman.

Falk, Richard (2002), La globalización depredadora. Una crítica, Madrid, Siglo XXI de España Editores.

Ferrer, Aldo (2006), Hechos y ficciones de la globalización. Argentina y el Mercosur en el sistema internacional. Buenos Aires, Fondo de Cultura Económica.

Ffrench-Davis, Ricardo (2001), «El comercio intralatinoamericano y su base analítica para el nuevo decenio", en Vittini, Iris, (compiladora), Los procesos de integración y cooperación regionales, Santiago, Convenio Andrés Bello, Instituto de Estudios Internacionales.

Ffrench-Davis, Ricardo (2007), «La reivindicación de la política económica y la equidad en un mundo globalizado", en Estudios Internacionales, $\mathrm{N}^{\circ} 157$, Santiago, Instituto de Estudios Internacionales, Universidad de Chile.

Foro Internacional sobre Globalización, FIG, (2003), Alternativas a la globalización económica. Barcelona, Gedisa.

Garretón, Manuel Antonio; Marcelo Cavarozzi, Peter Cleaves, Gary Gereffi y Jonathan Hartlyn (2004), América Latina en el siglo XXI. Hacia una nueva matriz sociopolitica, Santiago, Lom.

Gilpin, Robert (1975), «Three Models of the Future», en Bergsten, Fred y Lawrence Krause (eds.), World Politics and International Economics, Washington D.C.

-___- (2000), The Challenge of Global Capitalism, Princeton, Princeton University Press.

— (2001), Global Political Economy, Princeton, Princeton University Press.
Guerra-Borges, Alfredo (2002), Globalización e Integración Latinoamericana, México D.F., Siglo XXI Editores.

Guardia, Alexis (2001), Desde el epicentro de la globalización, Santiago, Ediciones Universidad Diego Portales.

Held, David y Anthony McGrew (2003), Globalización/Antiglobalización. Sobre la reconstrucción del orden mundial, Barcelona, Paidós.

Ianni, Octavio (2004), La sociedad global, México D.F., Siglo XXI Editores.

Korten, David (2005), Cuando las transnacionales gobiernan el mundo, Santiago, Editorial Cuatro Vientos.

Malen Seña, Jorge (2000), Globalización, comercio internacional y corrupción, Barcelona, Gedisa.

Martner, Gonzalo (2007), Remodelar el modelo. Reflexiones para el Bicentenario, Santiago, Lom.

Mayorga, Roberto; Joaquín Morales, Rodrigo Polanco (2004), Inversión extranjera, régimen jurídico y solución de controversias. Aspectos nacionales e internacionales. Santiago, Lexis Nexis.

Mingst, Karen (2001), Essentials of International Relations, Nueva York, Norton and Company.

Mold, Andrew (2004), "Una propuesta de gravar con impuestos unitarios las ganancias de las empresas transnacionales», Revista de la CEPAL No 82, abril.

Naudon, Carlos y Alberto Sepúlveda (1998), Introducción a la política mundial. Permanencias y mutaciones, Santiago, Ediciones Chile América CESOC.

OECD (2006), Trends and recent developments in foreign direct investment, París.

Ohmae, Keiniche (1997), El fin del Estadonación, Santiago, Editorial Andrés Bello.

Randle, Patricio (2004), Soberanía Global. Adónde lleva el mundialismo, Buenos Aires, Ediciones Ciudad Argentina.

Russett, Bruce y Harvey Starr, (1985), World Politics, Nueva York, W.H. Freeman and Company.

Saxe-Fernández, John; James Petras; Henry Veltmayer y Omar Nuñez (2004), Glo- 
balización, imperialismo y clase social, Buenos Aires, Grupo Editorial Lumen Humanitas.

Sierralta, Aníbal (2002), «El proceso de internacionalización de las empresas latinoamericanas», en Política Internacional, $\mathrm{N}^{\circ} 70$, Lima, Academia Diplomática del Perú.

Solé, Eulalia (2003), Qué es el comercio justo, Barcelona, RBA Libros.

Stiglitz, Joseph (2003), El malestar de la globalización, Buenos Aires, Taurus Alfaguara.

_- (2005), Cómo hacer que funcione la globalización, Buenos Aires, Taurus Alfaguara.

UNCTAD (2004), World Investment Report 2004: The Shift Towards Services, <www. unctad.org/en/docs/wir2004_en.pdf, consultado el 28 de septiembre de 2007>.

UNCTAD (2006), World Investment Report 2006: FDI From developing and transition economies: implications for development, <www.unctad.org/en/docs/ wir2006_en.pdf, consultado el 5 de octubre de $2007>$.

UNCTAD (2007): World Investment Report 2007: Transnational Corporations, Extractive Industries and Development, $<$ www.unctad.org/en/docs/wir2007_ en.pdf, consultado el 19 de octubre de 2007>.

Vargas Carreño, Edmundo (2007), Derecho Internacional Público de acuerdo a las normas y prácticas que rigen en el siglo XXI, Santiago, Editorial Andrés Bello.

Vega, Héctor (2001), Integración económica y globalidad. América latina y el Caribe, Santiago, Ediciones Tierra Mía.

Vernon, Raymond (1983), Soberanía en peligro. La difusión multinacional de las empresas de Estados Unidos, México D.F., Fondo de Cultura Económica.

Witker, Jorge (2003), Derecho de la competencia económica en el TLCAN, México D.F., Editorial Porrúa.

Zarka, Jean Claude (1995), Les institutions internationals, Paris, Ellipses Edition Marketing. 